\title{
A Pitfall of Cautiousness in Monetary Policy
}

\author{
Stéphane Dupraz ${ }^{1}$, Sophie Guilloux-Nefussi ${ }^{1}$, \\ \& Adrian Penalver ${ }^{1}$
}

March 2020, WP 758

\begin{abstract}
Central banks are often reluctant to take immediate or forceful actions in the face of new information on the economic outlook. To rationalize this cautious approach, Brainard's attenuation principle is often invoked: when a policy-maker is unsure of the effects of his policies, he should react less than he would under certainty. We show that the Brainard principle, while a wise recommendation for policy-making in general, runs into a pitfall when it is applied to a central bank setting monetary policy. For a central bank, concerns over uncertainty create a cautiousness bias: acting less is justified when taking as given the private sector's expectations of inflation, but acting less shifts these inflation expectations away from the central bank's inflation target. In response to the de-anchoring of expectations, the central bank can easily end up acting as much as it is initially reluctant to do, but without succeeding in putting inflation back on target. This pattern is a feature of policy under discretion: the central bank would often be better off tying its hands not to listen to its concerns about uncertainty. ${ }^{*}$
\end{abstract}

Keywords: Uncertainty, Inflation Expectations, Discretion vs. Commitment.

JEL classification: E31, E52, E58.

\footnotetext{
${ }^{1}$ Monetary policy and financial research department, Banque de France, 31 rue Croix des Petits Champs, 75001 Paris, stephane.dupraz@,banque-france.fr, sophie.guilloux-nefussi@,banque-france.com and adrian.penalver@banque-France.fr.

* We thank Gadi Barlevy, Mario Pietrunti, Ricardo Reis and Ulf Söderström for valuable discussions. The views expressed herein are those of the authors and do not necessarily reflect those of the Banque de France or the Eurosystem.
} 


\section{NON-TECHNICAL SUMMARY}

Central banks must set monetary policy under substantial uncertainty on the economic outlook, as well as the effects of their own policies. To this uncertainty they often react by attenuating their policy response, or by changing it only gradually. Brainard (1967) provided a rationale for this cautious approach to policy-making. In his seminal paper, he formally derived what came to be known as the Brainard principle: although a policy-maker who is uncertain of the economic outlook should act as if his best expectation were a sure outcome (Theil, 1957), a policy-maker who is uncertain of the effects of his own policies should act less than he would under certainty.

We show that the Brainard principle, while a wise recommendation for policy-making in general, runs into a pitfall when it is applied to a central bank setting monetary policy. For concreteness, we focus on interest-rate policies. When a dis-inflationary shock hits, the central bank can push inflation up by cutting interest rates. The Brainard principle would recommend that, if the central bank is uncertain of the precise effect of an interest-rate cut on inflation, it should cut interest rates by less, even if this means letting inflation fall somewhat below target. This recommendation, however, abstracts from the fact that inflation also depends on the private sector's expectations of inflation, a dimension that Brainard's original set-up does not incorporate. The central bank takes these inflation expectations as given when it acts under discretion, but if the private sector foresees that the central bank will attenuate its policy response, it forms lower inflation expectations. This pushes inflation further down, and forces the central bank to decrease rates further. The central bank easily ends up decreasing rates by as much as it is initially reluctant to do, but with an inflation rate further below target than if it had not been concerned about uncertainty.

We give the name cautiousness bias to this perverse incentive that turns the central bank's concerns over uncertainty against its own interests. The terminology is in direct reference to the inflation bias expounded by Kydland and Prescott (1977) and Barro and Gordon $(1983 a, b)$. Like the inflation bias, the cautiousness bias is a feature of policy under discretion: it arises because the central bank fails to internalize the effect of its policy on inflation expectations. Contrary to the inflation bias however, it does not arise from a desire by the central bank to set output above its natural level. It does not even require the central bank to care about stabilizing output, and applies equally to a central bank that has a single mandate to stabilize inflation only.

We study the cautiousness bias under various specifications of the Phillips curve relationship between output and inflation. In a New-Classical Phillips curve setup, we show that in response to shocks foreseen by the private sector, a cautious central bank ends up moving real rates by exactly as much as a central bank that disregards concerns over uncertainty would. However, despite ending up moving real rates by the same amount as a central bank that disregards concerns over uncertainty (which is also the optimal policy under commitment), a cautious central banker suffers greater volatility in inflation. In the spirit of Rogoff (1985)'s solution to the inflation bias, we show that society would be better-off appointing a central banker who discounts concerns over uncertainty relative to society, even if this means responding to unforeseen shocks too aggressively.

The New-Classical Phillips curve provides a simple exposition of the cautiousness bias, but abstract from modeling the dynamics in the interplay between interest rate decisions and the response of inflation expectations. Hence we study the dynamics induced by the cautiousness 
bias under the Sticky-Information Phillips curve of Mankiw and Reis (2002). With the StickyInformation Phillips curve, the private sector only gradually incorporates new information into its inflation expectations. As a result, when a negative shock hits inflation expectations move little at first, and the central bank is able to attenuate the decrease in interest rates. But as the private sector gradually realizes the resulting fall in inflation, inflation is pushed down further, forcing the central back to decrease rates further, ultimately by as much as if it had not been willing to attenuate policy. We also show that the cautiousness bias applies equally to the forward-looking New-Keynesian Phillips curve (NKPC), which remains the most commonly used Phillips curve in economic modeling.

\section{Consequences of Attenuating Policy when Expectations React}

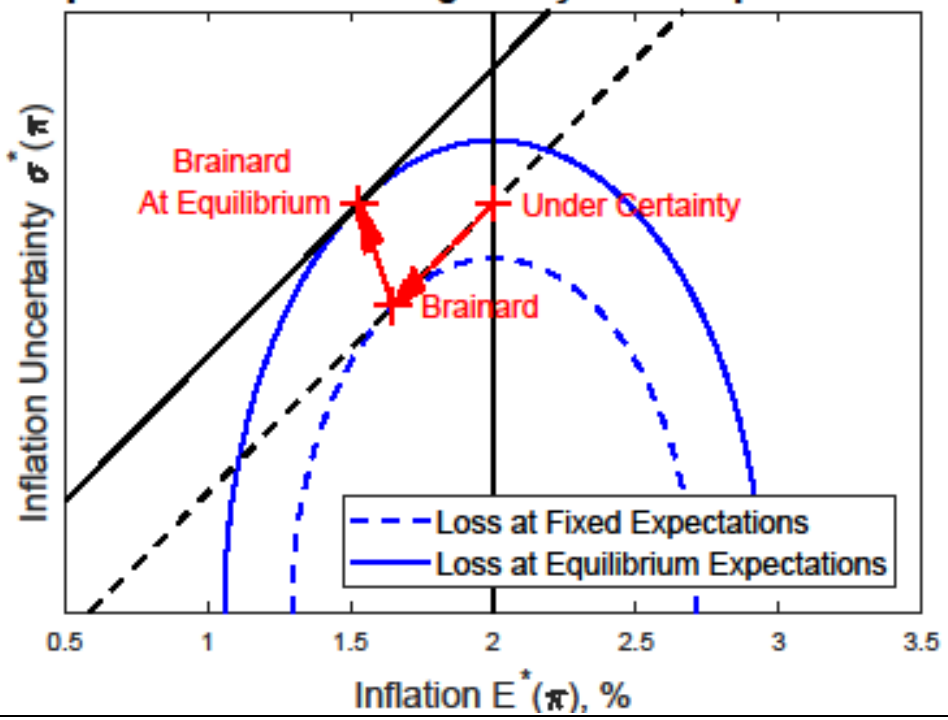

\section{Un écueil de la prudence en matière de politique monétaire}

\section{RÉSUMÉ}

Les banques centrales sont souvent réticentes à prendre des mesures immédiates ou de grande ampleur face à des informations nouvelles sur les perspectives économiques. Pour justifier cette approche prudente, le principe d'atténuation de Brainard est souvent invoqué : lorsqu'un décideur politique n'est pas sûr des effets de ses politiques, il devrait réagir moins qu'il ne le ferait en situation de certitude. Nous montrons que le principe de Brainard, bien que pertinent pour l'élaboration des politiques en général, se heurte à un écueil lorsqu'il est appliqué à une banque centrale en charge de la politique monétaire. Pour une banque centrale, les préoccupations relatives à l'incertitude créent un biais de prudence: il est justifié d'agir moins lorsque les anticipations d'inflation du secteur privé sont prises comme données. Mais en agissant moins, la banque centrale laisse ces anticipations s'écarter de la cible d'inflation. En réaction au désancrage des anticipations, la banque centrale peut facilement être obligée d'agir autant que ce qu'elle était réticente à faire au départ, mais sans réussir à ramener l'inflation au niveau visé. Ce processus est caractéristique d'un régime de politique monétaire discrétionnaire : la banque centrale ferait mieux de se lier les mains pour ne pas céder à ses préoccupations concernant l'incertitude.

Mots-clés : Incertitude, Anticipations d'Inflation, Discrétion/Engagement.

Les Documents de travail reflètent les idées personnelles de leurs auteurs et n'expriment pas nécessairement la position de la Banque de France. Ils sont disponibles sur publications.banque-france.fr 


\section{Introduction}

Central banks must set monetary policy under substantial uncertainty on the economic outlook, as well as the effects of their own policies. To this uncertainty they often react by attenuating their policy response, or by changing it only gradually. As a recent example, in March 2019 ECB President Mario Draghi explained the decision of the Governing Council in the following terms: "You just do what you think is right and you temper [with] a consideration [that] there is uncertainty. In other words, in a dark room you move with tiny steps." Draghi, 2019). In the US, FOMC member John Williams (2013) defended moderation in monetary policy on the same grounds.

Brainard (1967) provided a rationale for this cautious approach to policy-making. In his seminal paper, he formally derived what came to be known as the Brainard principle: although a policy-maker who is uncertain of the economic outlook should act as if his best expectation were a sure outcome (Theil, 1957), a policy-maker who is uncertain of the effects of his own policies should act less than he would under certainty. The logic of Brainard's attenuation principle is not limited to monetary policy, but it became widely known to central bankers in the 1990's thanks to Alan Blinder's book on his experience as a central banker (Blinder. 1999) 1

We show that the Brainard principle, while a wise recommendation for policy-making in general, runs into a pitfall when it is applied to a central bank setting monetary policy. For concreteness, we focus on interest-rate policies. When a dis-inflationary shock hits, the central bank can push inflation up by cutting interest rates. The Brainard principle would recommend that, if the central bank is uncertain of the precise effect of an interest-rate cut on inflation, it should cut interest rates by less, even if this means letting inflation fall somewhat below target. This recommendation, however, abstracts from the fact that inflation also depends on the private sector's expectations of inflation, a dimension that Brainard's original set-up does not incorporate. The central bank takes these inflation expectations as given when it acts under discretion, but if the private sector foresees that the central bank will attenuate its policy response, it forms lower inflation expectations. This pushes inflation further down, and forces the central bank to decrease rates further. The central bank easily ends up decreasing rates by as much as it is initially reluctant to do, but with an inflation rate further below target than if it had not been concerned about uncertainty.

We give the name cautiousness bias to this perverse incentive that turns the central bank's concerns over uncertainty against its own interests. The terminology is in direct reference to the inflation bias expounded by Kydland and Prescott (1977) and Barro and Gordon (1983a|b). Like the inflation bias, the cautiousness bias is a feature of policy under discretion: it arises because the central bank fails to internalize the effect of its policy on inflation expectations. Contrary to the inflation bias however, it does not arise from a desire by the central bank to set output above its natural level. It does not even require the central bank to care about stabilizing output, and applies equally to a central bank that has a single mandate to stabilize inflation only.

\footnotetext{
${ }^{1}$ Blinder was not only instrumental in popularizing Brainard's principle, but also in giving it its current interpretation of a rationale for "doing less". Blinder himself refers to the Brainard principle as the conservatism principle. We follows Reinhart (2003) in using the more neutral terminology of attenuation principle.
} 
To show the robustness of the cautiousness bias, we study it under various specifications of the Phillips curve relationship between output and inflation. In section 2, we start by explaining its logic with the New-Classical Phillips curve. We show that in response to shocks foreseen by the private sector, a cautious central bank ends up moving real rates by exactly as much as a central bank that disregards concerns over uncertainty would. However, despite ending up moving real rates by the same amount as a central bank that disregards concerns over uncertainty (which is also the optimal policy under commitment), a cautious central banker suffers greater volatility in inflation. In the spirit of Rogoff (1985)'s solution to the inflation bias, we show that society would be better-off appointing a central banker who discounts concerns over uncertainty relative to society, even if this means responding to unforeseen shocks too aggressively.

Although the case of the New-Classical Phillips curve provides a simple exposition of the cautiousness bias, its absence of dynamics prevents an analysis of the dynamics in the interplay between interest rate decisions and the response of inflation expectations. In section 3, we study the dynamics induced by the cautiousness bias under the Sticky-Information Phillips curve of Mankiw and Reis (2002). With the StickyInformation Phillips curve, the private sector only gradually incorporates new information into its inflation expectations. As a result, when a negative shock hits inflation expectations move little at first, and the central bank is able to attenuate the decrease in interest rates. But as the private sector gradually realizes the resulting fall in inflation, inflation is pushed down further, forcing the central back to decrease rates further, ultimately by as much as if it had not been willing to attenuate policy.

In section 4 we show that the cautiousness bias does not depend on the backward-looking nature of expectations in the New-Classical Phillips curve and Sticky-Information Phillips curve. It applies equally to the forward-looking New-Keynesian Phillips curve (NKPC), which remains the most commonly used Phillips curve in economic modeling. The timing in the manifestation of the bias is however different in this case, due to the front-loaded dynamics the NKPC is known to generate (Ball, 1994 , Mankiw and Reis, 2002). In response to a persistent fall in the natural rate, agents immediately expect that the central bank will let inflation fall below target in the future. As a result, the central bank is forced to decrease interest rates more as early as on impact. In this, the dynamics of the cautiousness bias under the NKPC resembles the one under the New-Classical Phillips curve.

The cautiousness bias we focus on in most of the paper consists of an overreaction of inflation to shocks. It does not create an incentive for a discretionary central bank to let average inflation depart form the inflation target $\pi^{*}$, in contrast to the inflation bias of Kydland and Prescott. In section 5, we show that this is only due to an implicit assumption of the frameworks used in previous sections. By generalizing the set-up, we show that the conflict between the desire to stabilize inflation and the desire to minimize inflation uncertainty can also lead to an average bias, just as the conflict between the desire to stabilize inflation and the desire to stabilize output can lead to both an inflation bias and a stabilization bias (Svensson, 1997).

For concreteness we analyze the cautiousness bias in the context of conventional interest-rate policies, but its logic applies equally to unconventional policies such as forward guidance and balance-sheet policies- 
at least when these are intended as alternative ways to stimulate aggregate demand. What is key to the cautiousness bias is not the way monetary policy affects aggregate demand, but the way aggregate demand affects inflation through the Phillips curve. Because unconventional policies are precisely the ones whose effects are likely to be deemed most uncertain (see, e.g., Williams, 2013), the importance for a central bank to be aware of a bias toward excessive caution is all the more important when the effective lower-bond (ELB) on nominal interest rates only leaves unconventional policies available.

The cautiousness bias has another implication for unconventional policies. Although in our framework real interest rates never move more than if the central bank had not tried to attenuate policy, nominal interest rates can. In the presence of the ELB, this implies that a central bank can find itself up against the ELB and forced to turn to unconventional policies even though it would not have, had it not tried to attenuate policy.

A number of papers have considered the implications of model uncertainty for the conduct of monetary policy. Svensson (1999); Clarida, Gali, and Gertler (1999); Estrella and Mishkin (1999); Sack (2000); Sack and Wieland (2000); Rudebusch (2001), and more recently Williams (2013), recover Brainard's recommendation for policy attenuation in the context of monetary policy. Subsequent literature has emphasized situations in which Brainard's attenuation principle is overturned and uncertainty calls instead for a more aggressive response 2 Söderström (2002), Kimura and Kirozumi (2007), and Ferrero, Pietrunti, and Tiseno (2019) consider such situations while still modeling the central bank's uncertainty in a Bayesian way, as in Brainard's original set-up (and ours). Söderström (2002) shows policy aggressiveness can be called for when uncertainty bears on the persistence of inflation, in a model with adaptive expectations. Kimura and Kirozumi (2007) show it is called for when uncertainty bears on the fraction of firms that form expectations in a rule-of-thumb, adaptive, fashion. Closer to this paper, Ferrero, Pietrunti, and Tiseno (2019) show that uncertainty on the slope of the New-Keynesian Phillips curve can lead the central bank to move nominal interest rates by more than under certainty in response to cost-push shocks, if shocks are persistent enough. We interpret the result through the lens of the cautiousness bias: the optimal discretionary policy is to attenuate the policy response for given inflation expectations, but the adverse reaction of inflation expectations forces the central bank to ultimately act more.

Other papers consider the consequences of modeling the central bank's uncertainty through the minmax approach of robust control instead of the Bayesian approach. They usually find that uncertainty calls for more aggressive policy, in opposition to the Brainard principle. Giannoni (2002) finds that the fear that the worst will happen to output and inflation if the central bank does not track the natural rate provides an incentive to track it more closely - i.e. to move interest rates more aggressively (see also Stock (1999); Onatski and Stock (2002); Tetlow and von zur Muehlen (2001); Söderström and Leitemo (2008)). Sargent (1999) finds that uncertainty on the persistence of shocks calls for a more aggressive response of monetary policy. Barlevy (2011) argues that what is conducive to more aggressive policy under robust control is less

${ }^{2}$ Brainard (1967)'s original paper already contains situations in which uncertainty calls for more aggressive policy, as we discuss in section 2. See also Chow (1973), Craine (1979) and Walsh (2003). 
the minmax approach per se than its application to specific situations 3 He gives examples where the minmax approach calls for policy attenuation, for the same reason as under the Bayesian approach, and shows that uncertainty on the persistence of shocks calls for policy aggressiveness in the Bayesian set-up as well 4

Other arguments for attenuation or gradualism have been put forward, which do not rely on the presence of uncertainty 5 Woodford (2003c) shows that the optimal, history-dependent, monetary policy under commitment features inertia, and can be approximated by a discretionary central bank that puts a cost on too abrupt a change in interest rates. Since Woodford's argument for gradualism does not rely on concerns over uncertainty however, it is not a rationale for attenuating or delaying the policy response more when uncertainty is higher. In particular, it is no rationale for being more reluctant to act when the only available instruments are unconventional instruments with more uncertain effects. As far as Odyssean forward guidance is concerned, it is precisely Woodford's argument in favor of inertia in interest rates that makes committing to keeping rates lower for longer recommendable (Eggertsson and Woodford, 2003).

A third argument for gradualism is based on concerns about the stability of the financial system. As argued by Cukierman (1991), interest-rate smoothing can be desirable because it mitigates sudden changes in banks' short-term funding cost or long-term asset returns, and therefore in banks' profits and balance-sheets. Interestingly, in a recent paper Stein and Sunderam (2018) show that this distinct motive for gradualism can also lead to a time-inconsistency problem: If the central bank dislikes volatile long-term rates for financial stability reasons, it has an incentive to track the natural interest rate only gradually, in order not to reveal information on long-term natural rates that would make long-term rates react too abruptly. But this is taking markets' expectations as given: in equilibrium markets understand that the central bank is moving gradually and adjust their expectations of long-term natural rates accordingly, partly undoing the central bank's efforts. We show that time-inconsistency is equally at play when gradualism is driven by uncertainty concerns. The time-inconsistency problem is different between the two models however: in our model the cautiousness bias arises from a failure to internalize inflation expectations, while in Stein and Sunderam's model time-inconsistency arises from a failure to internalize expectations of future interest rates - there are no inflation expectations in their model $]^{6}$

Finally, other costs of delaying policy action have been put forward. Acharya, Bengui, Dogra, and Wee (2019) show that under skill-loss hysteresis - when a prolonged period of unemployment depletes a worker's human capital - not acting promptly can push the economy into a recession from which it can then only slowly recover, and even not at all.

\footnotetext{
${ }^{3}$ See also Onatski and Williams $(2003)$ and Tillmann $(2009)$

${ }^{4}$ Using as well the minmax approach of robust control, Woodford (2010) and Adam and Woodford (2012) consider the design of monetary policy rules that are robust to the possibility that the private sector forms expectations using a wrong model, even though the central bank is itself sure of the model of the economy.

${ }^{5}$ Still other arguments have been put forward to explain gradualism positively, without defending it normatively. For instance, Riboni and Ruge-Murcia (2010) argue that gradualism in monetary policy is partly due to the consensus-building approach taken by many monetary policy committees, a decision-making procedure that favors the status quo.

${ }^{6}$ As a consequence, the cautiousness bias is at play in our model even though we make the New-Keynesian assumption that aggregate demand and inflation depend on the long-term — not short-term-interest rate. In Stein and Sunderam's model, for the time-inconsistency problem to be at play it is necessary that the central bank's interest-rate target bears on the short-term rate only.
} 


\section{A Simple Model of the Cautiousness Bias}

In this section, we expose the cautiousness bias in a simple model where the supply side is captured by the New Classical Phillips curve (Lucas, 1972). Using the New Classical Phillips curve has two advantages. First, it is the Phillips curve for which the bias appears most transparently. Second, it follows the classic accounts of the inflation bias by Kydland and Prescott (1977) and Barro and Gordon (1983ab).

\subsection{The Problem of the Central Bank}

The problem of the central bank is to pick an allocation for inflation $\pi_{t}$, the output gap $x_{t}$ and the nominal interest rate $i_{t}$ that best fits its objective, subject to the constraints imposed by the behavior of the private sector. These constraints are captured by a simple two-equation model. The aggregate-demand side of the economy is represented by the Euler equation:

$$
x_{t}=-\sigma\left(i_{t}-E_{t}\left(\pi_{t+1}\right)\right)+E_{t}\left(x_{t+1}\right)+v_{t},
$$

where $\sigma$ is the intertemporal elasticity of substitution, and $v_{t}$ is a possibly autocorrelated exogenous shock with mean zero, observable at period $t$. The shock $v_{t}$ captures variations in natural output $y_{t}^{n}$, or equivalently in the natural rate of interest $r_{t}^{n}$. Specifically, $v_{t}$ is the function $v_{t}=-\left(y_{t}^{n}-E_{t}\left(y_{t+1}^{n}\right)\right)$ of natural output, and connects to the natural rate through $v_{t}=\sigma r_{t}^{n}$. Appendix Aderives and discusses the connection between these alternative representations of the fundamental shocks to the Euler equation.

The aggregate supply side of the economy is captured by the New Classical Phillips curve:

$$
\pi_{t}=\kappa x_{t}+E_{t-1}\left(\pi_{t}\right)
$$

where $\kappa$ is the slope of the Phillips curve. The private sector's past expectations of present inflation, formed at $t-1$, shift the Phillips curve. The New Classical Phillips curve can be derived for instance under the assumption that a fraction of firms set their prices at $t$ with outdated information from $t-1$ (Woodford, 2003b Mankiw and Reis, 2010).

Crucially, the central bank faces model uncertainty. It is uncertain of the values of the structural parameter $\sigma$, and entertains several possible values for it. Like Brainard (1967), we follow Savage (1954) in modeling model uncertainty in a Bayesian way. The central bank assigns probabilities to every possible value of $\sigma$ and treats it as a random variable. We note $\bar{\sigma}$ and $V_{\sigma}$ the mean and variance of the central bank's subjective beliefs over $\sigma .7$ We assume the central bank is certain of the value of $\kappa$. We do so because assuming uncertainty bears only on $\sigma$ is the case most favorable to Brainard's attenuation principle, as will

\footnotetext{
${ }^{7}$ We implicitly assume that $V_{\sigma}$ is constant over time. This abstracts from the fact that the central bank could gradually gather information on the model of the economy through experience, effectively lowering its uncertainty $V_{\sigma}$ over time. Even with learning however, uncertainty over $\sigma$ would only be decreasing over time if the central bank can learn the structure of the economy faster than the structure of the economy changes. We implicitly assume that the structure of the economy is fast-changing so that we can take $V_{\sigma}$ to be constant.
} 
become clear below.

Although the central bank is uncertain of the model of the economy, we assume that the models it entertains are not too far from the actual one, in the spirit of rational expectations. We assume that the true value of $\sigma$ is $\bar{\sigma}$, the mean of the values considered by the central bank. The true dynamics of the economy is therefore given by the Euler equation (1) and Phillips curve (2) with $\sigma=\bar{\sigma}$. Note that we implicitly assume that the private sector is not subject to model uncertainty, since we assume that the Euler equation (1) and Phillips curve (2) hold, both of which are derived under the assumption of no model uncertainty. As a consequence, the central bank and the private sector have different information sets at $t$. To avoid any confusion, we denote by $E_{t}^{*}($.$) the expectations of the central bank at t$, which are formed without knowing $\sigma$. We reserve the notation $E_{t}($.$) for the expectations of the private sector, which knows that \sigma=\bar{\sigma}$. We assume that the private sector's expectations are part of the central bank's information set 8

We assume that the mandate of the central bank is to stabilize inflation only. Its objective is to set inflation $\pi_{t}$ to a target $\pi^{*}$ at all periods 9 It has the quadratic loss function:

$$
\mathcal{L}_{\infty}=E_{t}^{*}\left(\sum_{k=0}^{\infty} \beta^{k}\left(\pi_{t+k}-\pi^{*}\right)^{2}\right) .
$$

The assumption of a single inflation mandate is not necessary for our results. Appendix $\mathrm{D}$ shows that they hold equally well in the more general case in which the central bank has a dual objective to stabilize both inflation and the output gap. We focus on the case of a single mandate in the body of the paper for two reasons. First, it emphasizes that the cautiousness bias does not arise from a desire to stabilize output at the expense of stabilizing inflation, unlike the inflation bias. Therefore, it applies equally to central banks with a single primary mandate, like the ECB. In the appendix, we allow for the central bank to be willing to set output above potential and therefore be subject to the inflation bias, and show that the cautiousness bias and inflation bias arise from distinct perverse incentives. Second, the assumption of a single objective corresponds to the original framework of Brainard (1967).

\subsection{Reductio ad Brainard}

We now show that this simple monetary model exactly fits into the framework considered by Brainard (1967), up to one key difference: the presence of the expectations of the private sector. In its canonical form,

\footnotetext{
${ }^{8}$ Note that since the private sector's expectations depend on the parameter $\sigma$, the central bank could in theory solve for the dependence of expectations on $\sigma$ and infer the value of $\sigma$ from expectations. Such an inference is possible in our model because of the simplicity of its stylized two-equation set-up and the simplicity of its information structure. The mapping between $\sigma$ and expectations could be made arbitrary noisy by adding noise to the model, making the inference arbitrarily uninformative. Alternatively, we could assume that the private sector faces the same model-ambiguity as the central bank so that the central bank has nothing to learn from the private sector, but at the cost of less standard forms for the Euler equation and Phillips curve. Since the issue is peripheral to our focus, we simply assume away this inference from endogenous signals, as is common in the literature on incomplete perfect knowledge (e.g. Woodford (2003a) or Angeletos and La'O (2009)).

${ }^{9}$ With the New Classical Phillips curve 22 (and other information-based Phillips curves), the loss function that can be microfounded from the costs of relative price dispersion contains unexpected inflation, not inflation. However, since in practice the mandate of central banks bears on inflation, we assume so here. We consider any arbitrary inflation target (not necessarily zero) for the same reason. Considering other costs of inflation could justify caring about expected inflation (and various values for the inflation target) even when the Phillips curve is based on information frictions.
} 
Brainard's model considers a policy-maker who seeks to set a single variable on a target through the use of a single instrument. In our case, the single objective is inflation. We pick the single instrument of the central bank to be the real interest rate $r_{t} \equiv i_{t}-E_{t}\left(\pi_{t+1}\right){ }^{10}$

By taking expectations at $t-1$ of the New-Classical Phillips curve (2), it must be that the expected output gap next period is zero, $E_{t}\left(x_{t+1}\right)=0$. Plugging in the expression for the output gap from the Euler equation (1) into the Phillips curve (2), we get:

$$
\pi_{t}=-\phi r_{t}+\varepsilon_{t}+E_{t-1}\left(\pi_{t}\right)
$$

where we define $\phi \equiv \sigma \kappa$ and $\varepsilon_{t} \equiv \kappa v_{t}$. We denote $\bar{\phi}=\kappa \bar{\sigma}$ the mean of $\phi$ and $V_{\phi}=\kappa^{2} V_{\sigma}$ its variance.

Since the relationship (4) only contains period- $t$ variables, the objective of the central bank reduces to setting the interest rate $r_{t}$ to minimize the present-period loss:

$$
\mathcal{L}_{t}\left(\varepsilon_{t}\right)=E_{t}^{*}\left(\pi_{t}-\pi^{*}\right)^{2}
$$

at all periods $t$ and for all realizations of $\varepsilon_{t}$, subject to constraint (4). The following lemma takes stock, dropping the time subscripts as there is no ambiguity as to the time indexes.

Lemma 1 The program of the central bank is, for any realization of the shock $\varepsilon$, to pick the interest rate $r$ that minimizes

$$
\mathcal{L}(\varepsilon)=E^{*}\left(\left(\pi-\pi^{*}\right)^{2}\right)
$$

subject to:

$$
\pi=-\phi r+\varepsilon+E_{-1}(\pi)
$$

where the central bank observes $\varepsilon$ and $E_{-1}(\pi)$, and $\phi$ is a random variable with mean $\bar{\phi}$ and variance $V_{\phi}$.

Up to the expectations of the private sector $E_{-1}(\pi)$, this is exactly the framework considered by Brainard (1967). The random variable $\phi$ captures the policy-maker's uncertainty on how its own action, $r$, affects its objective $\pi$. In our case, it captures the central bank's uncertainty over the interest-rate channel. As Brainard emphasized, this is the type of uncertainty that can justify policy attenuation. Uncertainty over $\varepsilon$ only — in our case, uncertainty over the natural rate - would result in Theil's certainty equivalence: it would leave the optimal policy unchanged, up to replacing $\varepsilon$ by its expected value (Theil, 1957). Our assumption that the central bank perfectly observes $\varepsilon$ abstracts from this irrelevant form of uncertainty.

\footnotetext{
${ }^{10}$ To be sure, in practice the central bank sets a path for the nominal interest rate, but the implementation of the optimal policy is an issue distinct from the choice of the optimal policy, which is the one we consider here. The latter is a path for all three variables $i_{t}, \pi_{t}$ and $x_{t}$, subject to the constraints imposed by the Euler equation (1) and Phillips curve 22. Parameterizing the equilibrium through the three variables $r_{t}, \pi_{t}$ and $x_{t}$ is simply a convenient change of variables, and one that fits into Brainard's framework.
} 
We have restricted the uncertainty over the interest-rate channel to arise from uncertainty over $\sigma$, the elasticity of demand to changes in the real interest rate. It could also arise from uncertainty over $\kappa$, the elasticity of inflation to changes in demand. We focus on $\sigma$ because uncertainty over $\kappa$ would create correlation between $\varepsilon=\kappa v$ and $\phi=\kappa \sigma$. As Brainard notes, such correlation can turn the recommendation for policy attenuation into a recommendation for policy aggressiveness. Our qualification of the Brainard principle is distinct and does not rely on correlated shocks. Therefore, we restrict uncertainty to $\sigma$ to restrict to the standard case of uncorrelated shocks, which is the one most favorable to policy attenuation.

Our main point is that the presence of the private sector's expectations in the Brainard model (7) makes important changes to its policy recommendations. When the outcome of the policy depends on the expectations of the private sector, we need to distinguish between policy under discretion and policy under commitment. The cautiousness bias is a feature of policy under discretion, when the central bank takes the inflation expectations of the private sector as given. We start with this case.

\subsection{Brainard's Attenuation Principle}

We first show that if we fix the inflation expectations of the private sector, Brainard's attenuation principle holds unchallenged. To take explicit note of the fact that the central bank does not internalize its impact on expectations, we temporarily denote expectations $e(\pi)$ instead of $E_{-1}(\pi)$. For the moment they do not have to bear any resemblance to equilibrium outcomes.

To understand the trade-off at the heart of Brainard's attenuation principle, it is helpful to decompose the mean squared error in its loss function (6) into the square of the distance of average inflation from its target, and the variance of inflation:

$$
\begin{aligned}
\mathcal{L}(\varepsilon) & =\left(E^{*}(\pi)-\pi^{*}\right)^{2}+\operatorname{Var}^{*}(\pi), \\
\text { where }\left(E^{*}(\pi)-\pi^{*}\right)^{2} & =\left(-\bar{\phi} r+\varepsilon+e(\pi)-\pi^{*}\right)^{2}, \\
\text { and } \operatorname{Var}^{*}(\pi) & =V_{\phi} r^{2}
\end{aligned}
$$

This expression makes apparent the two-possibly conflicting - objectives of the central bank. It wants to bring its expectation of inflation (conditional on $\varepsilon$ ) to target, and it wants to minimize the (conditional) variance of inflation. Note that through both objectives - including the one of bringing expected inflation on target given the realization of $\varepsilon$ - the goal of the central bank is to minimize the overall variance of inflation. By setting the conditional expectation of inflation on target for every realization of $\varepsilon$ it minimizes the between variance of inflation. By minimizing the conditional variance of inflation is minimizes the within variance of inflation 11

Denote $r^{s}$ the interest rate that the central bank sets when it faces no model uncertainty, $V_{\phi}=0$. In this

\footnotetext{
${ }^{11}$ The unconditional loss function is equal to $\mathcal{L}=E(\mathcal{L}(\varepsilon))=(E(\pi)-\tilde{\pi})^{2}+\operatorname{Var}(E(\pi \mid \varepsilon))+E(\operatorname{Var}(\pi \mid \varepsilon))$, where the second term is the between variance of inflation and the third term is the within variance of inflation. They sum to the total variance of inflation by the law of total variance.
} 
case the central bank can focus on minimizing the first term 9 in its loss function, and can fully stabilize inflation on target by setting:

$$
r^{s}=\bar{r}^{n}+\frac{e(\pi)-\pi^{*}}{\bar{\phi}},
$$

where $\bar{r}^{n}$ denotes the natural rate in the average (and actual) model:

$$
\bar{r}^{n} \equiv \frac{\varepsilon}{\bar{\phi}}=\frac{v}{\bar{\sigma}} .
$$

According to equation (11), without concerns for model uncertainty, the optimal discretionary policy is to track the natural rate, plus a corrective term if inflation expectations are not on target. In this case, it is by responding fully to variations in the natural rate that the central bank reduces inflation volatility and stabilizes the economy.

When the central bank is uncertain of the impact of its rate decision on inflation, $V_{\phi}>0$, the policy rate $r$ affects not only the expected value of inflation $(9)$ but also its variance $(10)$. This new dependence captures the fact that, if the central bank is unsure of the consequences of departing from the steady-state rate $r=0$, its uncertainty is all the greater the larger the departure away from the steady-state rate. Because the policy rate now affects both terms, there is now a trade-off between reaching the inflation target on average (and minimizing the between variance of inflation), and minimizing the within variance of inflation. The central bank solves this trade-off by choosing a midpoint $r$ between the optimal interest-rate policy without model uncertainty $r_{s}$ which minimizes the first term, and the steady-state interest rate $r=0$ which minimizes the second term:

$$
\begin{gathered}
r=\alpha r^{s}, \\
\text { where } \alpha \equiv \frac{\bar{\phi}^{2}}{\bar{\phi}^{2}+V_{\phi}} .
\end{gathered}
$$

Policy becomes biased toward the steady-state interest rate $r=0$ because the central bank understand the effects of this policy better. Crucially, because $\alpha$ is less than one, the central bank no longer fully reacts to shocks to the natural rate. Uncertainty over the effects of the policy response calls for attenuating the policy response. This is Brainard's attenuation principle.

Note that under its optimal discretionary policy the central bank does not expect inflation to be on target. Plugging the chosen policy rate (13) into (7), the central bank expects inflation to be:

$$
E^{*}(\pi)=\pi^{*}+(1-\alpha)\left(\bar{\phi} \bar{r}^{n}+e(\pi)-\pi^{*}\right) \neq 0
$$

But the central bank is fine with this. It sees it as a cost worth paying to avoid the risks of uncertain policy outcomes. 


\subsection{The Reaction of Inflation Expectations}

The conclusion that the central central bank reacts less to shocks is premature however. The optimal discretionary policy (13) depends on the private sector's expectations of inflation, which are still to be solved for. Crucially, inflation expectations depend on what policy the private sector expects the central bank to implement. If a central bank concerned with model uncertainty fights inflation less aggressively, private agents are likely to take it into account in forming inflation expectations.

We solve for the rational expectations of the private sector. Injecting policy (13) into equation (7), taking expectations $E_{-1}$, and imposing rational expectations $e(\pi)=E_{-1}(\pi)$ yields:

$$
E_{-1}(\pi)=\pi^{*}+\left(\frac{1}{\alpha}-1\right) \bar{\phi} E_{-1}\left(\bar{r}^{n}\right)
$$

When the central bank faces no model uncertainty $\alpha=1$, inflation expectations are on target, since the private sector rightly anticipates that the central bank will set the policy rate so that inflation is on target under all circumstances. With model uncertainty $\alpha<1$ however, expectations of a natural rate above average leads the private sector to expect above-target inflation. The private sector rightly expects that in this case the cautious central bank will set the real interest rate below the natural rate, creating a positive output gap, and thus above-target inflation.

With the private sector's expectations of inflation solved for, we can finish solving for the optimal policy under discretion. Plugging expectations $(16)$ into the optimal policy rate $[13$, it becomes:

$$
r=E_{-1}\left(\bar{r}^{n}\right)+\alpha\left(\bar{r}^{n}-E_{-1}\left(\bar{r}^{n}\right)\right) .
$$

Do concerns over model uncertainty lead the central bank to indeed attenuate its policy response, as the Brainard principle usually predicts? Without concerns over uncertainty, $\alpha=1$, the optimal policy is to set the real interest rate equal to the natural rate (Woodford, 2003b). When $\alpha<1$, equation (17) shows that, in equilibrium, the central bank attenuates its response only to unforeseen changes in the natural rate. To foreseen changes it reacts exactly as much as if it had no concerns over uncertainty.

A cautious central bank ends up reacting just as much to foreseen shocks because its reluctance to act pushes inflation to the point at which it is forced to act by the same extent anyway. Assume a shock hits that pushes the natural rate below its average level. Concerned with uncertainty if it decreases its policy rate too low, the central bank decides not to fully track the decrease in the natural rate, even if it means letting inflation fall somewhat below target. But if the shock is foreseen by the private sector, this willingness of the central bank to tolerate below-target inflation is, too. Accordingly, the private sector expects lower inflation. Lower inflation expectations put further downward pressure on inflation. In response, the central bank decides to decrease its rate a little more but still in an attenuated manner, which justifies even lower inflation expectations, and so on. Ultimately, inflation expectations fall up to the point where they are low 
enough to convince the central bank to fully match the decrease in the natural rate, as it would have chosen in the absence of concerns for uncertainty.

\subsection{The Cautiousness Bias}

In reaction to foreseen shocks, the central bank ends up moving its policy rate as much as if it had no concerns over uncertainty, but inflation ends up further away from target. Formally, the overall departure from target - in response to both unforeseen shocks $\bar{r}^{n}-E_{-1}\left(\bar{r}^{n}\right)$ and foreseen shocks $E_{-1}\left(\bar{r}^{n}\right)$ - is:

$$
E^{*}(\pi)-\pi^{*}=(1-\alpha) \bar{\phi}\left(\left(\bar{r}^{n}-E_{-1}\left(\bar{r}^{n}\right)\right)+\frac{1}{\alpha} E_{-1}\left(\bar{r}^{n}\right)\right)
$$

In response to unforeseen shocks $\bar{r}^{n}-E_{-1}\left(\bar{r}^{n}\right)$, inflation ends up away from target, by $(1-\alpha) \bar{\phi}$ percentage points for every percentage-point change in the natural rate. This is the amount of inflation the central bank was willing to tolerate. But in response to foreseen shocks $E_{-1}\left(\bar{r}^{n}\right)$ inflation ends up further away from target, by an additional factor $1 / \alpha$. The outcome in terms of stabilizing inflation is worse than if the central bank ignored policy uncertainty. Since the policy rate is forced into the uncharted territory the central bank was seeking to avoid, the outcome is as bad in terms of avoiding uncertain outcomes. Overall, in response to foreseen shocks the central bank reaches a worse outcome than if it had not sought to act cautiously.

The result that the central bank is behaving against its own interest is a feature of policy under discretion. It would not be if policy were chosen under commitment, because this would allow the central bank to internalize the effect of its policy on expectations. Appendix B solves for the optimal policy under commitment and shows that the optimal allocation has the policy rate take the exact same value as under discretion (17) —attenuating the response to unforeseen shocks and fully responding to foreseen shocks — but gets a better inflation outcome. Under commitment, the departure of inflation from target is:

$$
E^{*}(\pi)-\pi^{*}=(1-\alpha) \bar{\phi}\left(\bar{r}^{n}-E_{-1}\left(\bar{r}^{n}\right)\right)
$$

Inflation takes the same value as under discretion in response to unforeseen shocks, but it remains on target in response to foreseen shocks. Under commitment, the central bank understands that when shocks are foreseen by the private sector, the policy rate can only be equal to the natural rate in equilibrium. It understands that a desire to vary the policy rate by less than the natural rate will only increase inflation expectations up to the point where inflation is enough off-target to convince the central bank to vary the policy rate by the full extent of the change in the natural rate. As a consequence, it does not attempt to attenuate the policy response to foreseen shocks and inflation remains on target. It does attenuate the response to unforeseen shocks, however, because these do not risk de-anchoring inflation expectations.

We give the name cautiousness bias to the perverse incentive that turns the central bank's cautiousness into a policy that is no less aggressive, but yields worse stabilization outcomes. Like the inflation bias 
expounded by Kydland and Prescott (1977) and Barro and Gordon (1983a b), the cautiousness bias arises because policy chosen under discretion abstracts from the effect of policy on expectations. It differs from the inflation bias however, in that it does not rely on the desire of the central bank to set output above its natural level. As our assumption of a single inflation mandate highlights, it does not even require the central bank to care about stabilizing output. It arises instead because of the distorted perception of the trade-off between stabilization inflation, and stabilizing the policy rate at values where its effects are better known.

\subsection{Guarding Oneself Against Being Cautious}

Short of shifting to deciding policy under commitment, what can a central bank-or the society that appoints it - do to guard itself against the cautiousness bias? Rogoff (1985) proposed a solution to realign the incentives of a discretionary policy-maker with the preferences of society under commitment: appoint a policy-maker whose preferences differ from society's.

We show that society would be better off appointing a central banker who is less cautious than society is. We capture different degrees of cautiousness through different weightings $\delta$ of the variance term in the loss function $(8), 12$

$$
\mathcal{L}(\varepsilon)=\left(E^{*}(\pi)-\pi^{*}\right)^{2}+\delta \operatorname{Var}^{*}(\pi)
$$

A discretionary central bank with such preferences still sets policy according to (13), up to a new value for the attenuation coefficient $\alpha$ :

$$
\alpha(\delta)=\frac{\bar{\phi}^{2}}{\bar{\phi}^{2}+\delta V_{\phi}} .
$$

We assume that society's true preferences are still captures by the loss function (8), i.e. the loss function (20) with $\delta=1$, and evaluate the outcome delivered by the various central bankers according to society's true social preferences. The choice of $\delta$ faces the following trade-off. A central bank that discounts uncertainty more reacts to shocks more. This reduces the cautiousness bias in response to foreseen shocks, but also means overreacting to unforeseen shocks. Appendix $\mathrm{C}$ solves for the optimal value of $\delta$. It shows that, unless all shocks are perfectly unforeseen by the private sector, it is always recommendable to have a central bank that discounts concerns over uncertainty, $\delta<1$. The exact extent of discounting increases with the proportion of shocks that are foreseen by the private sector. If all shocks are foreseen, then society should appoint a central banker who fully disregard concerns over uncertainty.

\footnotetext{
${ }^{12}$ The weighting parameter $\delta$ allows to encompass several reasons for different degrees of cautiousness. A central banker who perceives less uncertainty on the model parameter $\phi$ will be akin to one who has a lower $\delta$, since $\operatorname{Var}^{*}(\pi)=V_{\phi} r^{2}$. But differences in the degree of cautiousness can reflect pure differences in preferences: the weighting parameter $\delta$ can also be seen as capturing different degrees of risk-aversion within a class of (squared) mean-variance preferences. Finally, discounting the variance term can be a conscious decision to discount uncertainty concerns in order to counterbalance the cautiousness bias. In this last case, it resembles a form of limited commitment.
} 


\section{The Cautiousness Bias with the Sticky-Information Phillips Curve}

We now consider the cautiousness bias in a less stylized model of the economy's supply side: the StickyInformation Phillips curve of Mankiw and Reis (2002). While the New-Classical Phillips curve is useful to illustrate the logic of the cautiousness bias, its absence of dynamics misses an analysis of the chronology in the policy decisions and their consequences. With the New-Classical Phillips curve, the entire dynamics is subsumed into a one-period simultaneous equilibrium: because the private-sector anticipates that the central bank will fight deflationary shocks less aggressively at $t$, inflation expectations are lower at $t$, and the central bank is forced to act at $t$. More realistically, this sequence of events happens sequentially: A negative shock to the natural rate hits; the central bank does not fully track the fall in the natural rate; inflation falls below target; the private sector gradually realizes that inflation is below target and forms lower inflation expectations; lower inflation expectations push inflation down; the central bank is forced to decrease rates further. The Sticky-Information Phillips curve allows us to capture this sequence of events.

\subsection{The Problem of the Central Bank}

We assume the supply-side of the economy is captured by the Sticky-Information Phillips curve:

$$
\pi_{t}=\kappa x_{t}+\bar{E}_{t-1}\left(\pi_{t}+\zeta \Delta x_{t}\right)
$$

where $\zeta$ is the slope of the Short-Run Aggregate-Supply (SRAS), $\Delta x_{t}=x_{t}-x_{t-1}$ is the growth rate of the output gap, and $\bar{E}_{t-1}$ is notation for the following weighted average of expectations formed at different periods in the infinite past:

$$
\bar{E}_{t-1}\left(\pi_{t}+\zeta \Delta x_{t}\right)=\sum_{j=0}^{\infty} \lambda(1-\lambda)^{j} E_{t-1-j}\left(\pi_{t}+\zeta \Delta x_{t}\right)
$$

Like the New-Classical Phillips curve, the Sticky-Information Phillips curve models monetary non-neutrality as arising from price-setters' imperfect information. Contrary to the New-Classical Phillips curve, which assumes all information is incorporated by everyone after one period, the Sticky-Information Phillips curve assumes that the private sector only gradually learns about the shocks that hit the economy ${ }^{13}$

We only replace the Phillips curve and keep the Euler equation (1) unchanged on the aggregate-demand side. However, when the central bank is uncertainty of the value of the intertemporal elasticity of substitution $\sigma$, considering the Euler equation in its recursive or iterated forms matters. Each form makes different

\footnotetext{
${ }^{13}$ Specifically, it can be derived under the assumptions that a fraction $\lambda$ of firms updates their information sets every period, and that the probability of updating information in a given period is independent of how long it has been since the firm last updated its information. The slope of the Sticky-Information Phillips curve is a function of the probability $\lambda$ of renewing one's information set in a given period, $\kappa=\zeta \lambda /(1-\lambda)$.
} 
assumptions on the uncertainty of the central bank ${ }^{14}$ The recursive form of the Euler equation is:

$$
x_{t}=-\sigma r_{t}+E_{t}\left(x_{t+1}\right)+v_{t} .
$$

Its iterated form is:

$$
x_{t}=-\sigma R_{t}+E_{t}\left(\sum_{k=0}^{\infty} v_{t+k}\right)
$$

where $R_{t}$ is the long-term real interest rate:

$$
R_{t} \equiv E_{t}\left(\sum_{k=0}^{\infty} r_{t+k}\right)=r_{t}+E_{t}\left(R_{t+1}\right) .
$$

With the recursive Euler equation (24), the uncertainty of the central bank over the output gap - and therefore over inflation-is:

$$
\operatorname{Var}_{t}^{*}\left(x_{t}\right)=V_{\sigma} r_{t}^{2}
$$

It is the lowest when the short-term rate is equal to its steady-state value $r_{t}=0$. It captures that the central bank understands the effect of interest rates on demand best when the short-term rate is close to its steady-state value. With the iterated Euler equation (25), the uncertainty of the central bank over the output gap - and therefore over inflation-is:

$$
\operatorname{Var}_{t}^{*}\left(x_{t}\right)=V_{\sigma} R_{t}^{2}+\operatorname{Var}_{t}^{*}\left(E_{t}\left(\sum_{k=0}^{\infty} v_{t+k}\right)\right)
$$

It is the lowest when the long-term rate is equal to its steady-state value $R_{t}=0$. It captures that the central bank understands the effect of interest rates on demand best when the long-term rate is close to its steady-state value. But if the central bank wants to keep the long-term rate nears its steady-state value, then it want to keep the short-term rate near $r_{t}=-E_{t}\left(R_{t+1}\right)$, not near zero.

Both assumptions are meaningful. However, because what the output gap depends on, with an uncertain elasticity $\sigma$, is the whole long-term interest rate, the case when the central bank worries about departures of the long-run interest rate from steady-state is more natural. We consider this case in what follows, using the iterated Euler equation (25). The case when the central bank worries about departures of the short-term interest rate from steady-state is qualitatively similar 15

\footnotetext{
${ }^{14}$ The issue does not arise with the New-Classical Phillips curve because with the New-Classical Phillips curve the expected output gap next period is zero $E_{t}\left(x_{t+1}\right)=0$.

${ }^{15}$ An additional mechanism appears in this case, which tends to make the policy response more front-loaded. In response to a fall in the natural rate, the central bank can expect it will attenuate the decrease in the short-term policy rate tomorrow. As a result, the output gap today becomes more negative and inflation today falls more below target. The central bank is therefore more willing to decrease the short-term interest rate today in order to stabilize inflation today. It is forced into action even earlier on.
} 
Plugging in the iterated Euler equation 25 into the Sticky-Information Phillips curve 23] gives the relationship between the short-term interest rate $r_{t}$ chosen at $t$ and inflation $\pi_{t}$ at $t$. The problem of the central bank under discretion at $t$ follows.

Lemma 2 The program of the central bank at $t$ is to pick the short-term interest rate $r_{t}$ that minimizes the loss $\mathcal{L}_{t}=E_{t}^{*}\left(\left(\pi_{t}-\pi^{*}\right)^{2}\right)$, where inflation depends on the interest rate through:

$$
\pi_{t}=-\phi\left(r_{t}+E_{t}\left(R_{t+1}\right)\right)+\kappa E_{t}\left(\sum_{k=0}^{\infty} v_{t+k}\right)+\bar{E}_{t-1}\left(\pi_{t}+\zeta \Delta x_{t}\right),
$$

where $\phi=\kappa \sigma$. Because it acts under discretion, it takes future policies $E_{t}\left(R_{t+1}\right)$ as given.

\subsection{The Attenuation Principle in a Dynamic Set-Up}

The central bank still faces the same trade-off as under the New-Classical Phillips curve, between bringing its best expectations of inflation on target, and minimizing the (conditional) variance of inflation. Its loss function can be written $\mathcal{L}_{t}=\left(E_{t}^{*}\left(\pi_{t}\right)-\pi^{*}\right)^{2}+\operatorname{Var}_{t}^{*}\left(\pi_{t}\right)$, where:

$$
\begin{aligned}
\left(E_{t}^{*}\left(\pi_{t}\right)-\pi^{*}\right)^{2} & =-\bar{\phi}\left(r_{t}+E_{t}\left(R_{t+1}\right)\right)+\kappa E_{t}\left(\sum_{k=0}^{\infty} v_{t+k}\right)+\bar{E}_{t-1}\left(\pi_{t}-\pi^{*}+\zeta \Delta x_{t}\right), \\
\operatorname{Var}_{t}^{*}\left(\pi_{t}\right) & =V_{\phi}\left(r_{t}+E_{t}\left(R_{t+1}\right)\right)^{2}
\end{aligned}
$$

The interest rate that sets inflation on target - the one the central bank would set absent concerns over uncertainty -is:

$$
r_{t}^{s}=r_{t}^{n}+E_{t}\left(\sum_{k=1}^{\infty}\left(r_{t+k}^{n}-r_{t+k}\right)\right)+\frac{\bar{E}_{t-1}\left(\pi_{t}-\pi^{*}+\zeta \Delta x_{t}\right)}{\bar{\phi}}
$$

where we defined again the natural rate in the true model $r_{t}^{n}=v_{t} / \bar{\sigma}$. Without concerns over model uncertainty, the optimal discretionary policy is to track the natural rate, plus a corrective term if inflation expectations are not on target, and if monetary policy is expected not to track the natural rate tomorrow. In doing so, it has the long-term rate track the long-term natural rate, plus a corrective term if inflation expectations are not on target:

$$
\begin{aligned}
R_{t}^{s} & =R_{t}^{n}+\frac{\bar{E}_{t-1}\left(\pi_{t}-\pi^{*}+\zeta \Delta x_{t}\right)}{\bar{\phi}}, \\
\text { where } R_{t}^{n} & \equiv E_{t}\left(\sum_{k=0}^{\infty} r_{t+k}^{n}\right) .
\end{aligned}
$$

When the central bank is uncertain of the impact of interest rates on inflation, it sets the policy rate $r_{t}$ to a midpoint between the interest rate $r_{t}^{s}$ that puts inflation on target on average, and the interest rate 
$r_{t}=-E_{t}\left(R_{t+1}\right)$ that minimizes the within variance of inflation (31):

$$
r_{t}=\alpha r_{t}^{s}+(1-\alpha)\left(-E_{t}\left(R_{t+1}\right)\right)
$$

where $\alpha$ is still given by (14). This solution for the short-term rate sets the long-term interest rate to:

$$
R_{t}=\alpha\left(R_{t}^{n}+\frac{\bar{E}_{t-1}\left(\pi_{t}-\pi^{*}+\zeta \Delta x_{t}\right)}{\bar{\phi}}\right)
$$

Brainard's attenuation principle materializes once again as a bias toward the policy whose effects the central bank understands best: in our case, keeping long-term interest rates toward their steady-state value.

\subsection{Acting Tomorrow Out of Not Acting Today}

To assess whether - and for how long - the central bank can indeed attenuate its policy response, we need to solve for the private sector's expectations on which the policy rate 36 depends. To do so, we need to solve for the dynamics induced by this very policy. Appendix E shows that the dynamics of inflation and the output gap (in the true model) is determined by the system:

$$
\begin{aligned}
& x_{t}=\bar{\sigma} R_{t}^{n}-\frac{\alpha}{(1-\alpha) \kappa}\left(\pi_{t}-\pi^{*}\right), \\
& \pi_{t}=\kappa x_{t}+\bar{E}_{t-1}\left(\pi_{t}+\zeta \Delta x_{t}\right) .
\end{aligned}
$$

We consider the response of the economy (37)-38 to a persistent fall in the natural rate. We assume the shocks to the natural rate follow an $\operatorname{AR}(1)$ :

$$
r_{t}^{n}=\rho r_{t-1}^{n}+\eta_{t}
$$

in which case the long-term natural rate $R_{t}^{n}=r_{t}^{n} /(1-\rho)$ also does. We calibrate the model at a quarterly frequency, as follows. Following Mankiw and Reis (2002), we set the slope of the SRAS to $\zeta=0.1$, and the frequency of renewing one's information to once a year, $\lambda=0.25$. This gives a slope of the Phillips curve equal to $\kappa=\zeta \lambda /(1-\lambda)=0.033$. We set the intertemporal elasticity of substitution to $\bar{\sigma}=1$. We assume that the uncertainty of the central bank is such that it attenuates its response by a quarter, $\alpha=0.75$. We set the persistence of the shocks to $\rho=0.95$.

We consider a fall of the natural rate by one percentage point on impact. We solve for the ImpulseResponse Function (IRF) using the method of undetermined coefficients, as detailed in appendix E Figure 1 gives the responses of inflation, the output gap and interest rates. Because most private agents do not notice the shock on impact, on impact inflation expectations stay on target and the central bank fulfills its desire to attenuate the decrease in interest rates. As a result, inflation falls below target. Yet, as the private sector gradually realizes the fall in inflation, inflation is pushed down further, forcing the central back to decrease 
rates further. The real interest rate ends up tracking the fall in the natural rate as much as if the central bank had not been willing to attenuate policy. Even as the real rate converges to the natural rate however, inflation remains further below target than it would have if the central bank had not been concerned by uncertainty.

On figure 1, although the fall in the real rate never exceeds the fall in the natural rate, because of the fall in inflation expectations the nominal rate ends up falling by more that it would have absent concerns over uncertainty. Taking into account the effective lower bound (ELB) on interest-rate policies, a central bank subject to the cautiousness bias can therefore find itself up against the ELB even though it would not have if it had not try to attenuate policy early on.

\section{The Cautiousness Bias with the New-Keynesian Phillips Curve}

Both the New-Classical Phillips curve and the Sticky-Information Phillips curve make past expectations of present inflation the relevant inflation expectations. Does the cautiousness bias depend on this form of backward-lookingness in the Phillips curve? We show it does not: The cautiousness bias applies similarly to the forward-looking New-Keynesian Phillips curve (NKPC). The dynamics of events under the NKPC differs from the one under the Stick-Information Phillips curve. Because the NKPC is not based on the assumption that it takes time for agents to incorporate new information, inflation expectations are not sluggish. Monetary policy is not progressively forced into action as inflation expectations progressively adjust. Instead, inflation expectations respond strongly on impact, and monetary policy is forced into action on impact.

\subsection{The Problem of the Central Bank}

We assume the supply-side of the economy is captured by the New-Keynesian Phillips curve, where inflation expectations enter as present expectations of future inflation:

$$
\pi_{t}=\kappa x_{t}+\beta E_{t}\left(\pi_{t+1}\right)
$$

where $\beta \in(0,1)$ is firms' discount factor. We keep the Euler equation unchanged, again in its iterated form 25). Plugging in the iterated Euler equation 25) into the New-Keynesian Phillips curve 40, gives the relationship between the short-term interest rate $r_{t}$ chosen at $t$ and inflation $\pi_{t}$ at $t$. Because the NewKeynesian Phillips curve is slightly non-vertical in the long-run $\beta<1$, we focus on the case of a zero-inflation target $\pi^{*}=0$ in order to abstract from a desire to exploit a long-run trade-off between inflation and output. The problem of the central bank under discretion at $t$ follows.

Lemma 3 The program of the central bank at $t$ is to pick the short-term interest rate $r_{t}$ that minimizes the 

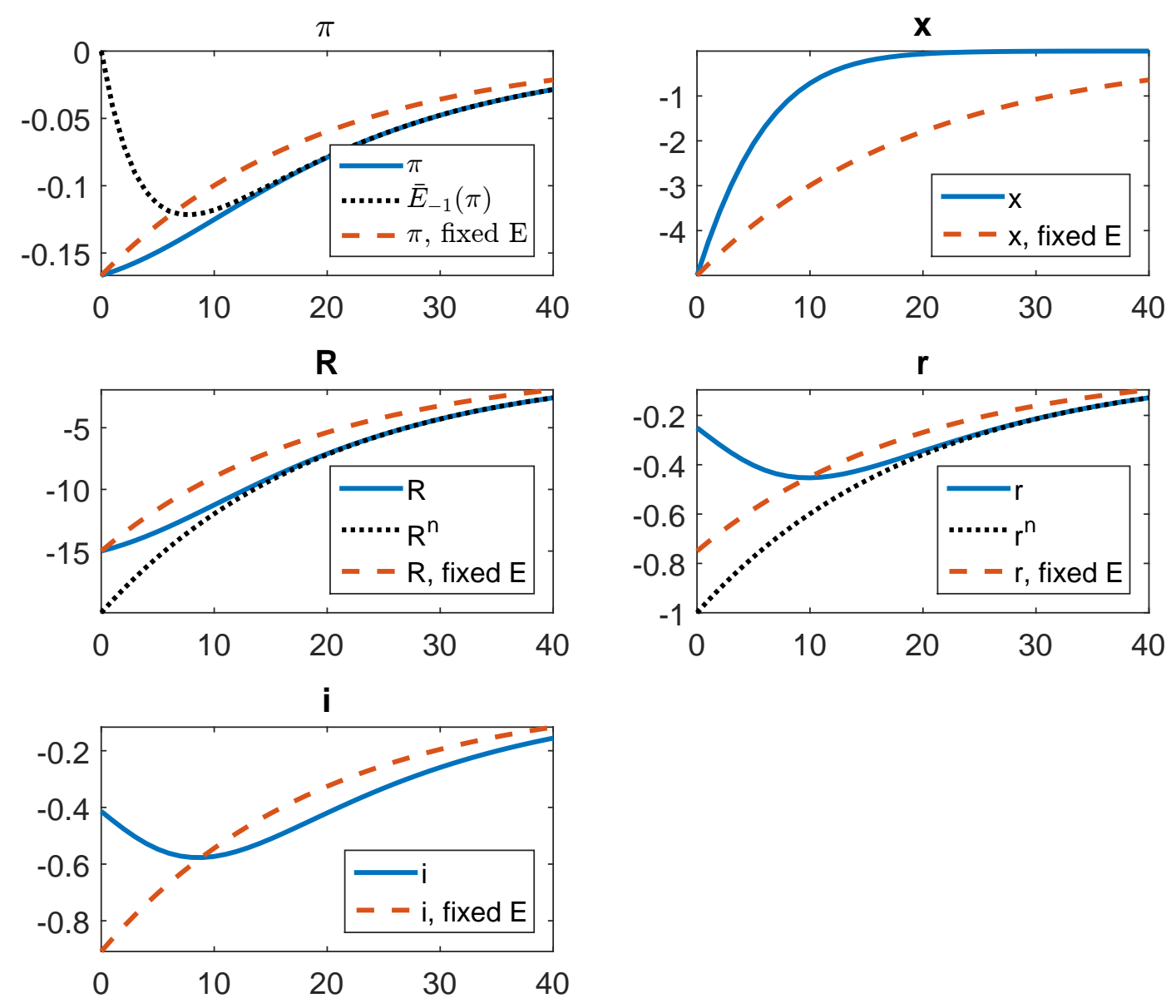

Figure 1: IRF to a Fall in the Natural Rate under the Sticky-Information Phillips Curve

Note: The figure gives the Impulse-Response Functions (IRF) of inflation $\pi$, the output gap $x$, the long-term real interest rate $R$, the short-term real interest rate $r$, and the short-term nominal interest rate $i$ to a $1 \mathrm{pp}$ decrease in the real natural rate of interest. The dotted lines give the IRF in the counterfactual case where expectations of inflation and output gap growth $\bar{E}_{t-1}\left(\pi_{t}+\zeta \Delta x_{t}\right)$ would remain constant to $\pi^{*}$. The horizon is expressed in quarters. The IRF are plotted under the following calibration. The intertemporal elasticity of substitution is $\bar{\sigma}=1$; the probability of renewing one's information set in the quarter is $\lambda=0.25$; the slope of the Short-Run Aggregate Supply relationship is $\zeta=0.1$. It implies a slope of the Phillips curve $\kappa=\zeta \times \lambda /(1-\lambda) \simeq 0.033$. The uncertainty $V_{\phi}$ is such that the central bank attenuates its action by a quarter, $\alpha=0.75$. The auto-regressive root of the $\operatorname{AR}(1)$ shock process is $\rho=0.95$.

loss $\mathcal{L}_{t}=E_{t}^{*}\left(\pi_{t}^{2}\right)$, where inflation depends on the interest rate through:

$$
\pi_{t}=-\phi\left(r_{t}+E_{t}\left(R_{t+1}\right)\right)+\kappa E_{t}\left(\sum_{k=0}^{\infty} v_{t+k}\right)+\beta E_{t}\left(\pi_{t+1}\right)
$$

where $\phi=\kappa \sigma$. Because it acts under discretion, it takes future policies $E_{t}\left(R_{t+1}\right)$ as given. 


\subsection{The Cautiousness Bias with Forward-Looking Inflation Expectations}

The derivation of the discretionary policy is similar to the case of the Sticky-Information Phillips curve. Appendix $F$ shows that the Brainard principle still applies: the optimal discretionary policy is to attenuate the response of the long-term interest rate to changes in the long-term natural rate by the factor $\alpha$,

$$
R_{t}=\alpha\left(R_{t}^{n}+\frac{\beta E_{t}\left(\pi_{t+1}\right)}{\bar{\phi}}\right)
$$

Once again however, the central bank acts less only for given inflation expectations, and acting less shifts inflation expectations adversely. Appendix $\mathrm{F}$ solves for inflation expectations in the case when the natural rate follows an $\mathrm{AR}(1)$ process 39 . It shows that in equilibrium, the long-term rate is then:

$$
R_{t}=\alpha\left(\frac{1}{1-\beta(1-\alpha) \rho}\right) R_{t}^{n}
$$

While Brainard's attenuation principle leads the central bank to move rates less by a factor $\alpha<1$, the reaction of inflation expectations forces the central bank to move rates more by a factor $1 /(1-\beta(1-\alpha) \rho)>1$. The cautiousness bias applies similarly to the New-Keynesian Phillips curve.

The timing in the manifestation of the cautiousness bias is specific to the New-Keynesian Phillips curve however. A well-known property of the NKPC is that it produces front-loaded dynamics, where shocks have their maximal effect on impact (Ball, 1994, Mankiw and Reis, 2002). This applies to the dynamics of the cautiousness bias. When a persistent negative shock to the natural rate hits, agents immediately factor in that the central bank will under-react to the fall in the natural rate, letting inflation fall below target. As a result, their present expectations of future inflation - the ones that enter the New-Keynesian Phillips curve -immediately fall. In reaction, the central bank is immediately forced to decrease interest rates further in order to counteract the fall in inflation expectations. The central bank is forced into action as early as on impact, and from then on the change to the real interest rate fades away in proportion to the change in the natural rate.

Inflation expectations react all the more that the shock is more persistent. They do not react at all if the shock is fully transitory $\rho=0$, and react most when $\rho$ tends to one. As a result, the central bank acts all the more that the shock is more persistent. In our model, the central bank always act less than it would have absent concerns over uncertainty, if acting more is defined in terms of the real interest rate. Even for very persistent shocks, the overall multiplier $\alpha /(1-\beta(1-\alpha) \rho)$ always remains below one 16 Appendix $\mathrm{G}$ shows that the same is true when the relevant Euler equation is the recursive Euler equation (24). Under either assumption on the Euler equation however, for persistent enough shocks, the central bank moves nominal interest rates by more than it would have absent concerns over uncertainty, as shown in appendices F and G.

\footnotetext{
${ }^{16}$ Since the short-term rate is $r_{t}=\alpha\left(\frac{1}{1-\beta(1-\alpha) \rho}\right) r_{t}^{n}$, the same is true of the short-term interest rate.
} 
That the persistence of shocks mitigates the policy attenuation called for by the Brainard principle is emphasized by Ferrero, Pietrunti, and Tiseno (2019). They consider a model where parameter uncertainty applies to the slope of the New-Keynesian Phillips curve $\kappa$ and show that the response of the central bank's nominal interest rate to cost-push shocks can move from attenuated to accentuated if shocks are persistent enough. We interpret their result through the lens of the cautiousness bias: a central bank concerned with Brainard uncertainty always wants to act less, but under discretion the adverse reaction of the private sector's expectations can force it to act more.

\section{A Cautiousness Bias on Average Inflation}

In all the analysis so far, the cautiousness bias has manifested itself as an overreaction of inflation to shocks. Because shocks are symmetric, the cautiousness bias has not challenged the ability of the central bank to set average inflation on target, in contrast to the inflation bias. In this section, we show that this is only due to an implicit assumption of the framework used so far. By generalizing the set-up, we show that the conflict between the desire to stabilize inflation and the desire to minimize inflation uncertainty can lead not only to an overreaction bias but also to an average bias, just as the conflict between the desire to stabilize inflation and the desire to stabilize output can lead to both an inflation bias and a stabilization bias (Svensson, 1997).

\subsection{Allowing for any Policy to be the Least Uncertain}

We consider again the framework of section 2, where the economy's supply-side is captured by the NewClassical Phillips curve (2). In the set-up of section 2, the unconditional average inflation rate ends up equal to the inflation target, $E(\pi)=\pi^{*}$. This can be seen by taking the unconditional average of the expression for expected inflation (16), and using the fact that the natural rate is at its steady-state value on average, $E\left(\bar{r}^{n}\right)=0$. While the cautiousness bias makes inflation more volatile around its target, it does not make average inflation depart from target 17

The absence of an average bias is however only due to an implicit assumption embedded in equation (7). The rationale for Brainard's attenuation principle is that, if the central bank is uncertain of the effects of its own action on inflation, uncertainty on inflation is all the greater the more it acts. Acting more however, is only defined relative to a reference point. In Brainard's framework, this reference point is the policy whose effects on inflation are best understood, in the sense of minimizing the conditional variance of inflation (10).

Equation (7) de facto assumes that the policy whose effects are best understood is keeping the interest rate around the steady-state value of the natural interest rate, $\bar{r}^{n}=0$. This can be a justifiable assumption. Because the steady-state natural rate is the interest rate that has been most often implemented, it can be argued it the interest rate on which most experience has been acquired. But this is an assumption, and

\footnotetext{
${ }^{17}$ Of course, the fact that average inflation is on target also depends on the fact that we shut down the inflation bias by considering a central bank with a single inflation mandate. See appendix $\mathrm{D}$ for the case where both the cautiousness and inflation biases are potentially at play.
} 
alternative ones are also defensible. For instance, it can be argued that the policy whose effects are best understood is keeping the interest rate toward the value that has been recently implemented, which may not correspond to the steady-state. Such an assumption is implicit in the reliance on the Brainard principle to justify gradualism, or the terminology of "conservatism principle" used by Blinder (1999) 18

In this section we generalize the set-up of section 2 to allow for the possibility that the policy whose effects are best understood is any arbitrary policy $\underline{r}$, not necessarily the steady-state natural interest rate $r=0$. Equation $(7)$ is now:

$$
\pi=-\phi(r-\underline{r})-\bar{\phi} \underline{r}+\varepsilon+E_{-1}(\pi)
$$

The constant term $-\bar{\phi} \underline{r}$ is necessary to guarantees that the central bank's average expectation of inflation across all the models it considers is correct, $E^{*}(\pi)=-\bar{\phi} r+\varepsilon+E_{-1}(\pi)$.

\subsection{Missing the Inflation Target on Average}

The program of the central bank is still to minimize the loss function (6), which can still be decomposed into a mean term (9) and a variance term. The only difference relative to section 2 is that, by definition, the within variance of inflation

$$
\operatorname{Var}^{*}(\pi)=V_{\phi}(r-\underline{r})^{2}
$$

is now minimized for $r=\underline{r}$. The central bank still solves the trade-off between its two objectives by setting the interest rate $r$ to a midpoint between the interest rate (11) that minimizes the mean term (9), and the interest rate $\underline{r}$ that minimizes the variance term 45 :

$$
r=\alpha r^{s}+(1-\alpha) \underline{r},
$$

where $r^{s}$ is till given by (11) and $\alpha$ is still given by (14).

Because the real interest rate does not track the natural rate one-for-one, inflation is not on target, which is anticipated by the private sector. Its rational expectations of inflation are:

$$
E_{-1}(\pi)=\pi^{*}+\left(\frac{1}{\alpha}-1\right) \bar{\phi}\left(E_{-1}\left(\bar{r}^{n}\right)-\underline{r}\right)
$$

\footnotetext{
${ }^{18}$ The importance of the reference point of minimal uncertainty was not lost to Brainard, who cautioned that "some care must be used in interpreting [the attenuation principle]. The gap in this context is not the difference between what policy was "last period" and what would be required to make the expected value of [the target variable] equal to [its target]. In the example we have used, the gap is the difference between the point where the variance of [the target variable] is least and [the policy instrument] required to give an expected value of [the target variable] equal to [its target]" (Brainard, 1967). Sack (1998) and Wieland (2000) embed the Brainard principle in a dynamic learning model to capture the interpretation of the Brainard principle as a recommendation for gradualism.
} 
It follows that unconditional average inflation is:

$$
E(\pi)=\pi^{*}-\left(\frac{1}{\alpha}-1\right) \bar{\phi} \underline{r} \neq \pi^{*}
$$

Only when $\underline{r}=0$ is average inflation on target $\pi^{*}$. If the central bank understands better how its policy affects inflation around a rate $\underline{r}>0$ greater that the steady-state natural rate, Brainard's attenuation principle provides an argument for setting the real interest rate above the natural interest rate on average. As a consequence, average inflation is below target $\pi^{*}$ on average. Conversely, if the central bank understands better how the economy works around a rate $\underline{r}<0$ lower that the steady-state natural rate, average inflation is above target $\pi^{*}$ on average.

Having average inflation not equal to $\pi^{*}$ could be desirable, since it could come with the benefit of less uncertain inflation. In order to assess whether the desire to let average inflation depart from $\pi^{*}$ constitutes a bias, appendix B solves for the optimal average inflation rate under commitment. It shows that regardless of the value of $\underline{r}$, the optimal average inflation rate is $\pi^{*} 19$ Therefore, the departure of average inflation from $\pi^{*}$ when $\underline{r} \neq 0$ is indeed a second manifestation of the cautiousness bias, this time on average inflation. Because the desire of the central bank to systematically tilt the real interest rate toward $\underline{r}$ is fully anticipated by the private sector, in equilibrium the central bank fails to do so and the real interest rate is still (17). The desire to tilt the interest rate toward $\underline{r}$ only results in an inflationary bias (if $\underline{r}<0$ ) or deflationary bias (if $\underline{r}>0$ ).

As a result, in the generic case when the best-understood policy is not the steady-state policy $\underline{r} \neq 0$, a discretionary central bank cannot follow a cautious strategy without failing to deliver on its inflation mandate on average inflation. Only in the particular case when the best-understood policy is the steady-state policy $\underline{r}=0$ can a cautious discretionary central bank deliver an average inflation rate in line with its inflation mandate. In this case, inflation is still off-target more often than if the central bank were not cautious, but symmetrically so.

\section{Conclusion}

Since Alan Blinder's book (Blinder, 1999) made Brainard's attenuation principle widely known to central bankers, the economic literature has found several instances in which the Brainard principle proved not robust, with uncertainty calling instead for a more aggressive policy response. Preempting the literature to come - and because Brainard's original paper already emphasized cases in which uncertainty called for policy aggressiveness-Blinder commented: "My intuition tells me that [Brainard's principle] is more general_or

\footnotetext{
${ }^{19}$ The inflation target is usually understood as the average inflation rate desired by the central bank, i.e. the optimal average inflation rate under commitment. Therefore, by referring to $\pi^{*}$ as the central bank's inflation target, we implicitly already assumed that $\pi^{*}$ is the average inflation rate under commitment. Appendix B shows it is indeed the case. It is not simply by definition of $\pi^{*}$ however: what the reduced-form preferences (6) assume by construction is only that $\pi^{*}$ minimizes the mean term of the loss function. With Brainard uncertainty, another average inflation rate could minimize the variance term if the central were able to affect the average real interest rate. But the Phillips curve constraint 22 imposes it cannot.
} 
at least more wise-in the real world than the mathematics will support. And I certainly hope it is, for I can tell you that it was never far from my mind when I occupied the Vice Chairman's office at the Federal Reserve."

In this paper, we made a distinct qualification to Brainard's attenuation principle. Focusing on situations in which uncertainty does rationalize policy attenuation, we showed that, when policy outcomes depend on the expectations of the private sector as in monetary policy, the desire to attenuate policy can backfire. It adversely shifts the private sector's inflation expectations, forcing the central bank to ultimately act as much, but for worse outcomes. Our analysis does not conclude that uncertainty does not justify moving cautiously. But it emphasizes that central banks face a bias toward being overly cautious. 


\section{References}

Acharya, S., J. Bengui, K. Dogra, and S. L. Wee (2019): "Slow Recoveries and Unemployment Traps: Monetary Policy in a Time of Hysteresis," Working Paper.

AdAm, K., And M. Woodford (2012): "Robustly optimal monetary policy in a microfounded New Keynesian model," American Economic Review, 59, 468-487.

Angeletos, G.-M., And J. LA'O (2009): "Noisy Business Cycles," NBER Macroeconomics Annual 2009, $24,319-378$.

BALl, L. (1994): "Credible disinflation with staggered price-setting," American Economic Review, 84(1), $282-289$.

Barlevy, G. (2011): "Robustness and Macroeconomic Policy," Annual Review of Economics, 3, 1-24.

Barro, R., and D. Gordon (1983a): "A Positive Theory of Monetary Policy in a Natural Rate Model," Journal of Political Economy, 91(4), 589-610.

- (1983b): "Rules, Discretion and Reputation in a Model of Monetary Policy," Journal of Monetary Economics, 12, 101-121.

Blinder, A. (1999): Central Banking in Theory and in Practice. MIT Press.

Brainard, W. (1967): "Uncertainty and the Effectiveness of Policy," American Economic Review, 57(2), $411-425$.

Chow, G. (1973): "Effect of Uncertainty on Optimal Control Policies," International Economic Review, $14(3), 632-645$.

Clarida, R., J. Gali, and M. Gertler (1999): "The Science of Monetary Policy: A New Keynesian Perspective," Journal of Economic Literature, 37, 1661-1707.

Craine, R. (1979): "Optimal Monetary Policy with Uncertainty," Journal of Economic Dynamics $\mathscr{E}$ Controls, 1, 59-83.

Cukierman, A. (1991): "Why Does the Fed Smooth Interest Rates?," in Monetary Policy on the 75th Anniversary of the Federal Reserve System, ed. by M. Belongia, pp. 111-147. Kluwer Academic Publishers.

DraGHI, M. (2019): "Transcripts of the press conference of March 7, 2019," ECB.

Eggertsson, G., And M. Woodford (2003): "The Zero Bound on Interest Rates and Optimal Monetary Policy," Brookings Papers on Economic Activity, 1, 139-211.

Epstein, L., And S. Zin (1989): "Substitution, Risk Aversion, and the Temporal Behavior of Consumption and Asset Returns: A Theoretical Framework," Econometrica, 57(4), 937-969.

Estrella, A., And F. Mishrin (1999): "Rethinking the Role of NAIRU in Monetary Policy: Implications of Model Formulation and Uncertainty," in Monetary Policy Rules, ed. by J. Taylor, pp. 405-436. NBER, University of Chicago Press.

Ferrero, G., M. Pietrunti, and A. Tiseno (2019): "Benefits of Gradualism or Costs of Inaction? Monetary Policy in Times of Uncertainty," Bank of Italy Working Paper. 
Giannoni, M. (2002): "Does Model Uncertainty Justify Caution? Robust Optimal Monetary Policy in a Forward-Looking Model," Macroeconomic Dynamics, 6, 111-144.

Greenwood, J., Z. Hercowitz, and G. Huffman (1988): "Investment, Capacity Utilization and the Real Business Cycle," American Economic Review, 78(3), 402-417.

Kimura, T., And T. Kirozumi (2007): "Optimal monetary policy in a micro-founded model with parameter uncertainty," Journal of Economic Dynamic \& Control, 31, 399-431.

Kydland, F., and E. Prescott (1977): "Rules Rather than Discretion: The Inconsistency of Optimal Plans," Journal of Political Economy, 85(3), 473-492.

LuCAs, R. (1972): "Expectations and the Neutrality of Money," Journal of Economic Theory, 4, 103-124.

Mankiw, G., and R. Reis (2002): "Sticky Information Versus Sticky Prices: A Proposal to Replace the New Keynesian Phillips Curve," Quarterly Journal of Economics, 117(4), 1295-1328.

- (2007): "Sticky Information in General Equilibrium," Journal of the European Economic Association, 5(2-3), 603-613.

(2010): "Imperfect Information and Aggregate Supply," in Handbook of Monetary Economics, Volume $3 A$, ed. by B. Friedman, and M. Woodford. Elsevier.

Onatski, A., And J. Stock (2002): "Robust Monetary Policy under Model Uncertainty in a Small Model of the U.S. Economy," Macroeconomic Dynamics, 6, 85-110.

Onatski, A., And N. Williams (2003): "Modeling Model Uncertainty," European Economic Association, $1(5), 1087-1122$.

Reinhart, V. (2003): "Manking Monetary Policy in an Uncertain World," Economic Policy Symposium, Federal Reserve Bank of Kansas City, Jackson Hole, Wyoming.

Riboni, A., and F. Ruge-Murcia (2010): "Monetary Policy by Committee: Consensus, Chairman Dominance, or Simple Majority," Quarterly Journal of Economics, 125(1), 363-416.

Rogoff, K. (1985): "The Optimal Degree of Commitment to an Intermediate Monetary Target," Quarterly Journal of Economics, 100, 1169-1189.

Rudebusch, G. (2001): "Is the Fed too Timid? Monetary Policy in an Uncertain World," Review of Economics and Statistics, 83(2), 203-217.

SACK, B. (1998): "Uncertainty, Learning, and Gradual Monetary Policy," Feds Working Papers 1998-34.

(2000): "Does the fed act gradually? A VAR analysis," Journal of Monetary Economics, 46, $229-256$.

Sack, B., And V. Wieland (2000): "Interest-Rate Smoothing and Optimal Monetary Policy: A Review of Recent Empirical Evidence," Journal of Economics and Business, 52, 205-228.

Sargent, T. (1999): "Comment on "Policy Rules for Open Economies" by Laurence Ball," in Monetary Policy Rules, ed. by J. Taylor, pp. 144-154. NBER, University of Chicago Press.

Savage, L. (1954): The Foundations of Statistics. Dover Publication Inc, New York. 
Söderström, U. (2002): "Monetary Policy with Uncertain Parameters," Scandinavian Journal of Economics, 104(1), 125-145.

SöDerström, U., and K. Leitemo (2008): "Robust Monetary Policy in the New-Keynesian Framework," Macroeconomic Dynamics, 12(S1), 126-135.

Stein, J., and A. Sunderam (2018): "The Fed, the Bond Market, and Gradualism in Monetary Policy," Journal of Finance, 73(3), 1015-1060.

Stock, J. (1999): "Comment on "Policy rules for inflation targeting" by Glenn Rudebusch and Lars Svensson," in Monetary Policy Rules, ed. by J. Taylor, pp. 253-259. NBER, University of Chicago Press.

Svensson, L. (1997): "Optimal Inflation Targets, "Conservative" Central Banks, and Linear Inflation Contracts," American Economic Review, 87(1), 98-114.

\section{1.}

Tetlow, R., and P. von zur Muehlen (2001): "Robust monetary policy with misspecified models: Does model uncertainty always call for attenuated policy?," Journal of Economic Dynamics 83 Controls, 25, 911-949.

Theil, H. (1957): "A Note on Certainty Equivalence in Dynamic Planning," Econometrica, 25(2), 346-349.

Tillmann, P. (2009): "Optimal Monetary Policy with an Uncertain Cost Channel," Journal of Money, Credit and Banking, 41(5), 885-906.

WALsh, C. (2003): "Implications of a Changing Economic Structure for the Strategy of Monetary Policy," Proceedings, Economic Policy Symposium, Jackson Hole, Federal Reserve Bank of Kansas City, pp. 297348.

Wieland, V. (2000): "Monetary policy, parameter uncertainty and optimal learning," Journal of Monetary Economics, 46, 199-228.

Williams, J. (2013): "A defense of moderation in monetary policy," Journal of Macroeconomics, 38, 137150.

Woodford, M. (2003a): "Imperfect common knowledge and the effects of monetary policy," in Knowledge, Information and Expectations in Modern Macroeconomics, ed. by J. S. P. Aghion, R. Frydman, and M. Woodford. Princeton University Press.

(2003b): Interest and Prices: Foundations of a Theory of Monetary Policy. Princeton University Press.

(2003c): "Optimal Interest-Rate Smoothing," Review of Economic Studies, 70, 861-886.

(2010): "Robustly Optimal Monetary Policy with Near-Rational Expectations," American Economic Review, 100(1), 274-303. 


\section{A Microfoundations of the Shocks to the Euler Equation}

In this appendix, we discuss the connection between the alternative representations of the shocks to the Euler equation: through shocks to the underlying fundamentals such as productivity $a_{t}$, through shocks to natural output $y_{t}^{n}$, through shocks to the variable $v_{t}=y_{t}^{n}-E_{t}\left(y_{t+1}^{n}\right)=-\sigma r_{t}^{n}$, or through shocks to the natural rate $r_{t}^{n}$. We show that when the central bank faces uncertainty over $\sigma$, only the first three are equivalent.

To do so, we first rederive the Euler equation (1) through a standard microfounded model with no capital and technology shocks as the only fundamental disturbance. A representative household consumes $C_{t}$, works $L_{t}$ hours, and invests in $B_{t}$ nominal riskless bonds in order to maximize intertemporal utility:

$$
E_{0} \sum_{t=0}^{\infty} \beta^{t}\left(\frac{C_{t}^{1-\frac{1}{\sigma}}}{1-\frac{1}{\sigma}}-\frac{L_{t}^{1+\psi}}{1+\psi}\right),
$$

where $\sigma$ is the intertemporal elasticity of substitution, $\psi$ is the inverse of the Frisch elasticity of labor, and $\beta \in(0,1)$ is the household's discount factor.

A unit of consumption costs the price $P_{t}$. A unit of labor is paid the nominal wage $W_{t}$. The household chooses to invest $B_{t}$ in nominal riskless bonds yielding the nominal interest rate $I_{t}$. The household receives nominal profits $\Omega_{t}$ from firms. He faces the flow budget constraint:

$$
P_{t} C_{t}+B_{t}=W_{t} L_{t}+\Omega_{t}+I_{t} B_{t-1},
$$

and an additional borrowing constraint that prevents it from entering Ponzi schemes. The household takes all prices as given. Its optimal labor supply decision is to equate its marginal rate of substitution to the real wage $w_{t}=W_{t} / P_{t}$ :

$$
L_{t}^{\psi} C_{t}^{\frac{1}{\sigma}}=w_{t} .
$$

The household's total consumption $C_{t}$ results from the consumption $C_{t}^{i}$ of a continuum $i \in[0,1]$ of individual goods. We assume standard CES preferences with an elasticity of substitution across goods $\theta$. The household's demand for good $i$ is therefore:

$$
C_{t}^{i}=\left(\frac{P_{t}^{i}}{P_{t}}\right)^{-\theta} C_{t}
$$

Firm $i$ produces good $i$ using the production function:

$$
Y_{t}^{i}=A_{t}\left(N_{t}^{i}\right)^{\alpha},
$$

where $A_{t}$ is an aggregate productivity shock. Under flexible prices, firm $i$ sets its price $P_{t}^{i}$ to maximize present-period profits, internalizing the demand curve A.4 it faces. Its charges a markup over marginal 
costs:

$$
P_{t}^{i}=\frac{\theta}{\theta-1} P_{t} \frac{w_{t}}{A_{t} \alpha\left(N_{t}^{i}\right)^{\alpha-1}}
$$

Define natural output as the value of output in a flexible-price equilibrium. In a flexible-price equilibrium all firms set the same price and $A_{t} \alpha N_{t}^{\alpha-1}=\frac{\theta}{\theta-1} w_{t}$, where $N_{t}$ is total labor demanded by firms. Combining the first-order conditions of the household and the firms and assuming that the goods and labor markets clear, $C_{t}=Y_{t}$ and $L_{t}=N_{t}$, gives natural output as a function of technology. Using lower-case variables to denote $\log$-deviations from a steady-state with $A=1$, it is given by:

$$
y_{t}^{n}=\frac{\psi+1}{1+\psi+\left(\frac{1}{\sigma}-1\right) \alpha} a_{t} .
$$

Natural output is a function of the exogenous shock $a_{t}$. Note that natural output depends on the parameter $\sigma$, but only because the standard preferences we have assumed make $\sigma$ parameterize both the intertemporal elasticity of substitution, and the income effect on labor supply. Natural output depends on the strength of the income effect but not on the intertemporal elasticity of substitution. What we assume to be uncertain to the central bank is the intertemporal elasticity of substitution, not the strength of the income effect. Therefore, we assume that model uncertainty does not affect the central bank's expectations of natural output.20

The household's investment decision results in the Euler equation. Taking into account goods marketclearing $C_{t}=Y_{t}$, it writes in log-linear form:

$$
y_{t}=-\sigma\left(i_{t}-E_{t}\left(\pi_{t+1}\right)\right)+E_{t}\left(y_{t+1}\right)
$$

The Euler equation applies in particular under flexible prices, in which case it residually gives the real interest rate in the flexible-price equilibrium, that is, the natural rate:

$$
r_{t}^{n}=-\frac{1}{\sigma}\left(y_{t}^{n}-E_{t}\left(y_{t+1}^{n}\right)\right)
$$

To rewrite the Euler equation in difference to natural output, define the output gap $x_{t} \equiv y_{t}-y_{t}^{n}$. The Euler equation write:

$$
\begin{aligned}
& x_{t}=-\sigma\left(i_{t}-E_{t}\left(\pi_{t+1}\right)\right)+E_{t}\left(x_{t+1}\right)+v_{t}, \\
& v_{t} \equiv-\left(y_{t}^{n}-E_{t}\left(y_{t+1}^{n}\right)\right) .
\end{aligned}
$$

\footnotetext{
${ }^{20}$ There are several ways to make the parameter $\sigma$ play the role of the elasticity of substitution only, and therefore to explicitly eliminate the dependence of natural output on $\sigma$. For instance, we could assume GHH preferences (Greenwood, Hercowitz, and Huffman, 1988 to eliminate the income effect on labor supply. Alternatively, we could disentangle the intertemporal elasticity of substitution and the income effect on labor supply through Epstein-Zin preferences (Epstein and Zin 1989). However, in both cases the Euler equation would slightly differ from its canonical form. We thus stick to the standard preferences.
} 
The disturbance $v_{t}$ is a function of natural output, therefore of the exogenous shocks. Since $r_{t}^{n}=\frac{1}{\sigma} v_{t}$, in models where agents face no model uncertainty it is customary to write the shock $v_{t}$ to the Euler equation as exogenous variations in the natural rate:

$$
x_{t}=-\sigma\left(i_{t}-E_{t}\left(\pi_{t+1}\right)-r_{t}^{n}\right)+E_{t}\left(x_{t+1}\right) .
$$

However, the two representations A.10 and A.12 are not equivalent when the central bank faces uncertainty over $\sigma$. The variables $a_{t}, y_{t}^{n}$ and $v_{t}$ are independent of the intertemporal elasticity of substitution, while $\sigma$ enters the definition A.9 of $r_{t}^{n}$. Parameterizing the shocks to the Euler equation through an exogenous distribution for $r_{t}^{n}$ in equation A.12 would spuriously make the effect of disturbances appear dependent on the value of $\sigma$, whereas $\sigma$ multiplies $r_{t}^{n}$ in equation A.12 only because $r_{t}^{n}$ is divided by $\sigma$ in definition (A.9). While the issue is irrelevant in models without parameter uncertainty, it matters when the central bank faces uncertainty on $\sigma$, because it changes the value of $i_{t}$ for which the variance of $x_{t}$ is minimal.

\section{B Optimal Policy Under Commitment}

When the central bank sets policy under commitment, it understands the effect of its policy on the inflation expectations of the private sector. Because it understands that the private sector forms rational expectations in accordance with (7), it understand that in equilibrium its policy $r$ must satisfy:

$$
E_{-1}(r)=E_{-1}\left(r^{n}\right)
$$

Because the constraint B.1] on policy rates spreads across realizations of $\varepsilon$, the program of the central bank no longer reduces to independent programs for each realization of $\varepsilon$. Instead, the central bank's faces one program at each information node of the private sector. At each node, it chooses the policy rates $r(\varepsilon)$ in each final realization of the shock, and the unique expectation of the private sector $e$ to minimize:

$$
\begin{aligned}
\min _{(r(\varepsilon))_{\varepsilon}, e} E_{-1}(\mathcal{L}(\varepsilon)) & =E_{-1}\left(\left(-\bar{\phi}\left(r(\varepsilon)-r^{n}(\varepsilon)\right)+e-\pi^{*}\right)^{2}+V_{\phi} r(\varepsilon)^{2}\right), \\
\text { s.t. } E_{-1}(r(\varepsilon)) & =E_{-1}\left(r^{n}(\varepsilon)\right) .
\end{aligned}
$$

Noting $2 \lambda$ the Lagrange multiplier on the constraint, the F.O.C are:

$$
\begin{array}{lr}
\forall \varepsilon, / r(\varepsilon): & \bar{\phi}^{2}\left(r(\varepsilon)-r^{n}(\varepsilon)-\frac{e-\pi^{*}}{\bar{\phi}}\right)+V_{\phi} r(\varepsilon)+\lambda=0, \\
/ e: & e=E_{-1}\left(\bar{\phi}\left(r(\varepsilon)-r^{n}(\varepsilon)\right)+\pi^{*}\right) .
\end{array}
$$


Taking expectations $E_{-1}$ of the F.O.C $(\overline{B .4})$ and using the constraint (B.3) solves for $\lambda$. Substituting the expression for $\lambda$ in the F.O.C solves for $r(\varepsilon)$ :

$$
r(\varepsilon)=E_{-1}\left(r^{n}(\varepsilon)\right)+\alpha\left(r^{n}(\varepsilon)-E_{-1}\left(r^{n}(\varepsilon)\right)\right)
$$

The policy rate takes the exact same value as under discretion (17). Using the constraint (B.3), the F.O.C. B.5 gives $e=\pi^{*}$. Inflation expectations are always on target. Substituting the policy rate B.6 into equation (7) gives the departure of inflation from target under commitment (19).

In section 5 , we generalize the set-up of section 2 by replacing equation (7) by equation (44). The optimal policy under commitment keeps setting expected inflation on target $E_{-1}(\pi)=\pi^{*}$ in this case, and therefore unconditional average inflation on target, $E(\pi)=\pi^{*}$. Indeed, the only difference wrt. the case $\underline{r}=0$ is to replace the first-order condition (B.4) by:

$$
\forall \varepsilon, / r(\varepsilon): \bar{\phi}^{2}\left(r(\varepsilon)-r^{n}(\varepsilon)-\frac{e-\pi^{*}}{\bar{\phi}}\right)+V_{\phi}(r(\varepsilon)-\underline{r})+\lambda=0
$$

Equation (B.5) is unchanged. By taking its expectation and using the constraint (B.3), it still gives $e=\pi^{*}$. Following the same steps as in the case $\underline{r}=0$, one can also check that the policy rate still takes the value B.6 in this generalized case, as it does under discretion.

\section{Optimal Discounting of Uncertainty Concerns}

A central banker that puts a weight $\delta \geq 0$ on the variance term in the loss function 200 sets the interest rate to $r^{d}=\alpha r^{s}$, where $\alpha=\frac{\bar{\phi}^{2}}{\bar{\phi}^{2}+\delta V_{\phi}}$. As $\delta$ increases from zero to infinity, $\alpha$ decreases from 1 to 0 : the more concerned he is about uncertainty, the less he reacts to shocks. We can therefore parameterize the central banker's type by how aggressively he reacts to shocks, as captured by $\alpha$. An $\alpha$-type central banker acting under discretion delivers an inflation rate of:

$$
E^{*}(\pi)-\pi^{*}=(1-\alpha) \bar{\phi}\left(\frac{1}{\alpha} E_{-1}\left(r^{n}\right)+\left(r^{n}-E_{-1}\left(r^{n}\right)\right)\right)
$$

Society compares these outcomes using its loss function with $\delta=1$. The average loss generated by an $\alpha$-type central banker is:

$$
E[\mathcal{L}(\varepsilon)]=\operatorname{Var}\left(E^{*}(\pi)-\pi^{*}\right)+\operatorname{Var}^{*}(\pi) .
$$


The two terms write:

$$
\begin{aligned}
\operatorname{Var}\left(E^{*}(\pi)-\pi^{*}\right) & =(1-\alpha)^{2} \bar{\phi}^{2}\left(\frac{1}{\alpha^{2}} V_{E}+V_{U}\right) \\
\operatorname{Var}^{*}(\pi) & =V_{\phi}\left(V_{E}+\alpha^{2} V_{U}\right)
\end{aligned}
$$

where $V_{E} \equiv \operatorname{Var}\left(E_{-1}\left(r^{n}\right)\right)$ is the variance of fluctuations in the natural rate that are expected by the private sector, and $V_{U}=\operatorname{Var}\left(r^{n}-E_{-1}\left(r^{n}\right)\right)$ is the variance of fluctuations in the natural rate that are unexpected by the private sector. Therefore, society wants to appoint the central banker whose $\alpha$ minimizes:

$$
E[\mathcal{L}(\varepsilon)]=\left((1-\alpha)^{2} \bar{\phi}^{2}+\alpha^{2} V_{\phi}\right)\left(\frac{1}{\alpha^{2}} V_{E}+V_{U}\right)
$$

Taking the $\log$ and differentiating in $\alpha$, the optimal $\alpha$ satisfies:

$$
\frac{\alpha V_{\phi}-(1-\alpha) \bar{\phi}^{2}}{(1-\alpha)^{2} \bar{\phi}^{2}+\alpha^{2} V_{\phi}}=\frac{1}{\alpha+\alpha^{3} \frac{V_{U}}{V_{E}}}
$$

The right-hand-side term is decreasing from infinity to $V_{E} /\left(V_{E}+V_{U}\right)$ as $\alpha$ increase from 0 to 1 . Define the left-hand-side term as the function $f$ :

$$
f(\alpha)=\frac{\alpha-\alpha^{*}}{(1-\alpha)^{2} \alpha^{*}+\alpha^{2}\left(1-\alpha^{*}\right)},
$$

where $\alpha^{*}=\frac{\bar{\phi}^{2}}{\bar{\phi}^{2}+V_{\phi}}$ is the value of $\alpha$ of the central banker who has the same preferences as society, $\delta=1$. The LHS $f$ is negative for $\alpha<\alpha^{*}$, so it can only cross the RHS over $\left[\alpha^{*}, 1\right]$. The derivative of $f$ as the sign of the quadratic polynomial $P(\alpha)=-\alpha^{2}+2 \alpha^{*} \alpha+\alpha^{*}\left(1-2 \alpha^{*}\right)$. The polynomial reaches its maximum at $\alpha=\alpha^{*}$ and has two real roots. If $\alpha^{*}>1 / 2$, the larger root is greater than 1 , so $P$ is positive over [ $\left.\alpha^{*}, 1\right]$. It follows that $f$ is increasing over $\left[\alpha^{*}, 1\right]$. There is a unique crossing of the RHS and LHS terms in equation C.6. If $\alpha^{*}<1 / 2$, then the second root is smaller than 1 , so $f$ is increasing then decreasing over $\left[\alpha^{*}, 1\right]$. Yet, since $f(1)=1>V_{E} /\left(V_{E}+V_{U}\right)$, there is still a unique crossing of the RHS and LHS terms in equation C.6. In both cases, the two curves cross at a value greater than $\alpha^{*}$, unless $V_{E}=0$, in which case the RHS is constantly equal to zero and crosses the LHS at zero. An increase in $V_{E} /\left(V_{E}+V_{U}\right)$ corresponds to the RHS shifting up: the optimal $\alpha$ therefore increases with the fraction of shocks that are expected by the private sector.

\section{Proof in the Case of a Dual Mandate}

We generalize the case of a single inflation mandate considered in the main text of section 2 to allow for a dual objective to stabilize both inflation and the output gap. In doing so, we also allow for the possibility that the central bank seeks to set output above potential $x^{*}>0$, which will result in an inflation bias. The 
present-period loss of the central bank is:

$$
\mathcal{L}(\varepsilon)=E^{*}\left(\left(\pi-\pi^{*}\right)^{2}\right)+\lambda E^{*}\left(\left(x-x^{*}\right)^{2}\right),
$$

where $\lambda$ is the preference weight of the central bank on stabilizing the output gap. The dependences on the real interest rate of the output gap

$$
x=-\sigma r+v
$$

and inflation

$$
\pi=\kappa(-\sigma r+v)+e(\pi)
$$

are unchanged. The mean squared errors in the loss function (D.1) can still be decomposed into a terms for squared distances to targets and a term for variances:

$$
\begin{aligned}
& \mathcal{L}(\varepsilon)=\left(\left(E^{*}(\pi)-\pi^{*}\right)^{2}+\lambda\left(E^{*}(x)-x^{*}\right)^{2}\right)+\left(\operatorname{Var}^{*}(\pi)+\lambda \operatorname{Var}^{*}(x)\right), \\
& \text { where }\left(E^{*}(\pi)-\pi^{*}\right)^{2}+\lambda\left(E^{*}(x)-x^{*}\right)^{2}=\left(-\kappa \bar{\sigma} r+\varepsilon+e(\pi)-\pi^{*}\right)^{2}+\lambda\left(-\bar{\sigma} r+v-x^{*}\right)^{2}, \\
& \text { and } \operatorname{Var}^{*}(\pi)+\lambda \operatorname{Var}^{*}(x)=\left(\kappa^{2}+\lambda\right) V_{\sigma} r^{2}
\end{aligned}
$$

Denote $r^{s}$ the interest rate that the central bank sets when it faces no model uncertainty, $V_{\sigma}=0$. In this case the central bank can focus on minimizing the first term (D.5) in its loss function. It sets:

$$
r^{s}=r^{n}+\frac{\kappa}{\bar{\sigma}\left(\kappa^{2}+\lambda\right)}\left(e(\pi)-\pi^{*}\right)-\frac{\lambda}{\bar{\sigma}\left(\kappa^{2}+\lambda\right)} x^{*} .
$$

A desire to stabilize the output gap $\lambda>0$ changes the optimal discretionary policy under no concerns for uncertainty in two ways. First, the central bank reacts less to departures of inflation expectations from target. This is regardless of whether the central bank seeks to set output above potential $x^{*}>0$. Second, when $x^{*}>0$ the central bank seeks to set the interest rate lower in order to set the output gap higher. This last feature of the discretionary policy results in Kydland and Prescott (1977) and Barro and Gordon (1983ab)'s inflation bias. Rational expectations of inflation are above target:

$$
E_{-1}(\pi)=\pi^{*}+\frac{\lambda}{\kappa} x^{*}>\pi^{*}
$$

but the output gap is $x=021$

\footnotetext{
${ }^{21}$ Monetary policy could surprise the private sector by responding to unexpected shocks to the natural interest rate, which would make the output gap depart from zero (although it would need to be zero on average). The central bank has no interest in doing so here however, because there are no cost-push shocks.
} 
When the central bank is uncertain of the impact of its rate decision on inflation and the output gap, $V_{\sigma}>0$, the policy rate $r$ also affects the variance term 10 in the loss function. The central bank solves this problem by choosing a midpoint $r$ between the optimal interest-rate policy without model uncertainty $r_{s}$ which minimizes the first term, and the steady-state interest-rate $r=0$ which minimizes the second term:

$$
r=\alpha r^{s}
$$

where $\alpha$ is still given by 14 .

We solve for the rational expectations that this policy generates. Injecting policy (D.9) into equation (7), taking expectations $E_{-1}$, and imposing rational expectations $e(\pi)=E_{-1}(\pi)$ yields:

$$
E_{-1}(\pi)=\pi^{*}+\left(\frac{1}{\alpha}-1\right) \frac{\bar{\sigma}\left(\kappa^{2}+\lambda\right)}{\kappa} E_{-1}\left(r^{n}\right)+\frac{\lambda}{\kappa} x^{*}
$$

Inflation expectations can deviate from target for two reasons. First is the inflation bias, as noted in the case of no concerns for uncertainty: a desire to set output above potential $\lambda>0$ results in higher inflation expectations. Second is the cautiousness bias: a concern over parameter uncertainty $\alpha<1$ results in lower

(higher) inflation expectations when the natural rate is below (above) steady-state. The generalization to the case of a dual mandate shows both that the cautiousness bias is robust to a dual mandate, and that the cautiousness bias and inflation bias arise from distinct perverse incentives.

Plugging expectations (D.10) into the optimal policy rate (D.9), the expression for the real interest rate is exactly the same (17) as under a single inflation mandate. In equilibrium the central bank attenuates its response only to unforeseen changes in the natural rate. It does so in exactly the same proportions as in the case of a single inflation mandate.

\section{E Dynamics System and IRF in the Case of the SIPC}

Injecting the solution 36 for the long-term interest-rate into the Euler equation 25) (of the true model) gives the output gap as:

$$
x_{t}=\bar{\sigma}(1-\alpha) R_{t}^{n}-\frac{\alpha}{\kappa} \bar{E}_{t-1}\left(\pi_{t}-\pi^{*}+\zeta \Delta x_{t}\right)
$$

Using the Sticky-Information Phillips curve 23) to replace the last expectation term gives equation (37). Equation 38 is simply the Sticky-Information Phillips curve.

We solve for the IRF to a natural rate shock using the method of undetermined coefficients, following Mankiw and Reis (2007). Under the assumption of an $\operatorname{AR}(1)$ process for the natural rate $r_{t}^{n}$, and denoting 
$\hat{\pi}_{t}=\pi_{t}-\pi^{*}$ the deviation of inflation from its target, the dynamic system writes:

$$
\begin{aligned}
x_{t} & =\frac{\bar{\sigma}}{1-\rho} r_{t}^{n}-\frac{\alpha}{(1-\alpha) \kappa} \hat{\pi}_{t}, \\
\hat{\pi}_{t} & =\kappa x_{t}+\bar{E}_{t-1}\left(\hat{\pi}_{t}+\zeta \Delta x_{t}\right),
\end{aligned}
$$

Under the assumption of an $\mathrm{AR}(1)$ process for the natural rate $r_{t}^{n}$, its Wold decomposition is:

$$
r_{t}^{n}=\sum_{k=0}^{\infty} \rho^{k} \eta_{t-k}
$$

We look for a solution where $\hat{\pi}_{t}$ and $x_{t}$ are functions of the fundamental shock only. We write their Wold decompositions:

$$
\begin{aligned}
\hat{\pi}_{t} & =\sum_{k=0}^{\infty} \phi_{k}^{\pi} \eta_{t-k}, \\
x_{t} & =\sum_{k=0}^{\infty} \phi_{k}^{x} \eta_{t-k},
\end{aligned}
$$

with coefficients $\left(\phi_{k}^{\pi}\right)_{k}$ and $\left(\phi_{k}^{x}\right)_{k}$ to be determined. To translate the dynamic system E.2 - E.3 into equations on $\phi_{k}^{\pi}$ and $\phi_{k}^{x}$, note that:

$$
\bar{E}_{t-1}\left(\pi_{t}+\zeta \Delta x_{t}\right)=\sum_{k=1}^{\infty}\left(1-(1-\lambda)^{k}\right)\left(\phi_{k}^{\pi}+\zeta\left(\phi_{k}^{x}-\phi_{k-1}^{x}\right)\right) \eta_{t-k}
$$

The dynamic system (E.2)- E.3 therefore writes:

$$
\begin{aligned}
& \sum_{k=0}^{\infty} \phi_{k}^{x} \eta_{t-k}=\frac{\bar{\sigma}}{1-\rho} \sum_{k=0}^{\infty} \rho^{k} \eta_{t-k}-\frac{\alpha}{(1-\alpha) \kappa} \sum_{k=0}^{\infty} \phi_{k}^{\pi} \eta_{t-k} \\
& \sum_{k=0}^{\infty} \phi_{k}^{\pi} \eta_{t-k}=\kappa \sum_{k=0}^{\infty} \phi_{k}^{x} \eta_{t-k}+\sum_{k=1}^{\infty}\left(1-(1-\lambda)^{k}\right)\left(\phi_{k}^{\pi}+\zeta\left(\phi_{k}^{x}-\phi_{k-1}^{x}\right)\right) \eta_{t-k}
\end{aligned}
$$

Identifying the coefficients, it implies the following difference equations in $\left(\phi_{k}^{\pi}\right)_{k}$ and $\left(\phi_{k}^{x}\right)_{k}$ :

$$
\begin{aligned}
& \forall k \geq 0, \phi_{k}^{x}=\frac{\bar{\sigma}}{1-\rho} \rho^{k}-\frac{\alpha}{(1-\alpha) \kappa} \phi_{k}^{\pi}, \\
& \forall k \geq 1, \phi_{k}^{\pi}=\kappa \phi_{k}^{x}+\left(1-(1-\lambda)^{k}\right)\left(\phi_{k}^{\pi}+\zeta\left(\phi_{k}^{x}-\phi_{k-1}^{x}\right)\right),
\end{aligned}
$$

For $k=0, \phi_{0}^{\pi}=\kappa \phi_{0}^{x}$. 
Using equation E.11 to eliminate $\phi_{k}^{\pi}$ in E.10 gives the following first-order difference equation in $\phi_{k}^{x}$ :

$\forall k \geq 1,\left((1-\lambda)^{k}+\frac{\alpha}{1-\alpha}\left(1+\frac{\zeta}{\kappa}\left(1-(1-\lambda)^{k}\right)\right)\right) \phi_{k}^{x}=\left(\frac{\alpha \zeta}{(1-\alpha) \kappa}\left(1-(1-\lambda)^{k}\right)\right) \phi_{k-1}^{x}+\frac{\bar{\sigma}}{1-\rho} \rho^{k}(1-\lambda)^{k}$

This gives $\phi_{k}^{x}$ as a function of $\phi_{k-1}^{x}$. We obtain the entire sequence of $\left(\phi_{k}^{x}\right)_{k}$ from the initial condition $\phi_{0}^{x}=\frac{(1-\alpha) \bar{\sigma}}{1-\rho}$. We then recover the solution for inflation from E.11. The solutions for the interest rates follow.

\section{F Derivation in the Case of the NKPC}

The interest-rate that sets inflation on target is:

$$
r_{t}^{s}=R_{t}^{n}-E_{t}\left(R_{t+1}\right)+\frac{\beta E_{t}\left(\pi_{t+1}\right)}{\bar{\phi}} .
$$

The interest-rate that minimizes the within variance of inflation is $r_{t}=-E_{t}\left(R_{t+1}\right)$. The central bank sets its policy-rate to the weighted average (35) of these two rates. This makes the long-term rate equal to the expression in equation 42. Injecting the long-term rate into 411 (for the true model) gives inflation as:

$$
\pi_{t}=(1-\alpha)\left(\bar{\phi} R_{t}^{n}+\beta E_{t}\left(\pi_{t+1}\right)\right)
$$

Under the assumption that $r_{t}^{n}$ follows an $\mathrm{AR}(1)$ process 39 , the solution to $(\mathrm{F} .2)$ is :

$$
\pi_{t}=\frac{(1-\alpha) \bar{\phi}}{1-\beta(1-\alpha) \rho} R_{t}^{n}
$$

This implies that the private sector forms expectations of inflation:

$$
E_{t}\left(\pi_{t+1}\right)=\frac{(1-\alpha) \bar{\phi}}{1-\beta(1-\alpha) \rho} \rho R_{t}^{n}
$$

Injection these inflation expectations into the solution for the long-run rate 42 gives 43 . The short-term rate $r_{t}=R_{t}-E_{t}\left(R_{t+1}\right)$ is similarly:

$$
r_{t}=\alpha\left(\frac{1}{1-\beta(1-\alpha) \rho}\right) r_{t}^{n}
$$

It follows that the ex-ante nominal long-term interest rate $I_{t}=R_{t}+E_{t}\left(\sum_{k=0}^{\infty} \pi_{t+k+1}\right)$ is:

$$
I_{t}=\left(\frac{\alpha+(1-\alpha) \bar{\phi} \frac{\rho}{1-\rho}}{1-\beta(1-\alpha) \rho}\right) R_{t}^{n}
$$


whereas it is $I_{t}=R_{t}^{n}$ absent concerns over uncertainty. The coefficient in front of $R_{t}^{n}$ tends toward infinity as $\rho$ tends toward 1. Therefore, for persistent enough shocks, the central bank ends up moving the nominal long-term interest rate by more than it would have absent concerns over uncertainty. Since the nominal short-term interest-rate $i_{t}=r_{t}+E_{t}\left(\pi_{t+1}\right)$ is similarly:

$$
i_{t}=\left(\frac{\alpha+(1-\alpha) \bar{\phi} \frac{\rho}{1-\rho}}{1-\beta(1-\alpha) \rho}\right) r_{t}^{n}
$$

the same conclusion applies to the nominal short-term rate.

\section{G The Case of the NKPC and Recursive Euler Equation}

Plugging the recursive Euler equation (25) into the NKPC (40), the relationship between the short-term interest-rate chosen at $t$ and inflation at $t$ is:

$$
\pi_{t}=-\phi r_{t}+\kappa E_{t}\left(x_{t+1}\right)+\kappa v_{t}+\beta E_{t}\left(\pi_{t+1}\right)
$$

where $\phi=\kappa \sigma$. Because the central bank acts under discretion, it chooses $r_{t}$ at $t$ taking $E_{t}\left(x_{t+1}\right)$ and $E_{t}\left(\pi_{t+1}\right)$ as given. It does so to minimize the loss $\mathcal{L}_{t}=E_{t}^{*}\left(\pi_{t}^{2}\right)$. The interest-rate that sets inflation on target is:

$$
r_{t}^{s}=r_{t}^{n}+\frac{E_{t}\left(x_{t+1}\right)}{\bar{\sigma}}+\frac{\beta E_{t}\left(\pi_{t+1}\right)}{\bar{\phi}}
$$

The interest-rate that minimizes the within variance of inflation is $r_{t}=0$. The central bank sets its policyrate to the weighted average of these two rates:

$$
r_{t}=\alpha r_{t}^{s}
$$

Injecting this solution for the short-term interest rate into (G.1) and using the NKPC 40 to replace future output gap $E_{t}\left(x_{t+1}\right)$ gives inflation (in the true model) as:

$$
\pi_{t}=(1-\alpha)\left(\bar{\phi} r_{t}^{n}+(1+\beta) E_{t}\left(\pi_{t+1}\right)-\beta E_{t}\left(\pi_{t+2}\right)\right) .
$$

This is a second-order difference equation in $\pi_{t}$. Noting $F$ the forward time-series operator, the stationary solution is:

$$
\pi_{t}=\left[I-(1-\alpha)(1+\beta) F+(1-\alpha) \beta F^{2}\right]^{-1}(1-\alpha) \bar{\phi} r_{t}^{n}
$$


Under the assumption that $r_{t}^{n}$ follows an $\mathrm{AR}(1)$ process 39 , the solution to G.5 is:

$$
\pi_{t}=\frac{(1-\alpha) \bar{\phi}}{1-(1-\alpha)(1+\beta) \rho+(1-\alpha) \beta \rho^{2}} r_{t}^{n} .
$$

Expectations of inflation $E_{t}\left(\pi_{t+1}\right)$ and of the output gap $E_{t}\left(x_{t+1}\right)$ follow. Plugging them into the expression for the short-term interest-rate G.3 gives the solution for the short-term interest-rate:

$$
r_{t}=\alpha\left(\frac{1}{1-(1-\alpha) \rho(1+\beta(1-\rho))}\right) r_{t}^{n} .
$$

As in the case of the iterated Euler equation, Brainard's attenuation principle leads the central bank to move rates less by a factor $\alpha<1$ but the reaction of inflation expectations forces the central bank to move rates more, this time by a factor $1 /(1-(1-\alpha) \rho(1+\beta(1-\rho)))>1$. Inflation expectations react all the more that the shock is more persistent. The central bank varies the real interest-rate by more than the natural rate if and only if the coefficient on $r_{t}^{n}$ in G.7 is greater than 1. This happens if and only if the second-order polynomial:

$$
P(\rho)=\beta \rho^{2}-(1+\beta) \rho+1
$$

takes negative values. Because the roots of the polynomial are 1 and $1 / \beta$, this never happens for $\rho \in[0,1]$. However, as in the case of the iterated Euler equation, the short-term nominal interest-rate can vary more than if the central bank has no concerns over Brainard uncertainty. Indeed, the solution for the short-term nominal interest-rate $i_{t}=r_{t}+E_{t}\left(\pi_{t+1}\right)$ is:

$$
i_{t}=\left(\frac{\alpha+(1-\alpha) \bar{\phi} \rho}{1-(1-\alpha) \rho(1+\beta(1-\rho))}\right) r_{t}^{n}
$$

The coefficient in front of $r_{t}^{n}$ tends toward $1+\left(\frac{1-\alpha}{\alpha}\right) \bar{\phi}>1$ as $\rho$ tends toward 1 . Therefore, for persistent enough shocks, the central bank ends up moving the nominal short-term interest rate by more than it would have absent concerns over uncertainty. 